\title{
THRESH-Software for Tracking Rainfall Thresholds for Landslide and Debris-Flow Occurrence, User Manual
}

Chapter 2 of

Section A, Modeling Methods

Book 14, Landslide and Debris-Flow Assessment

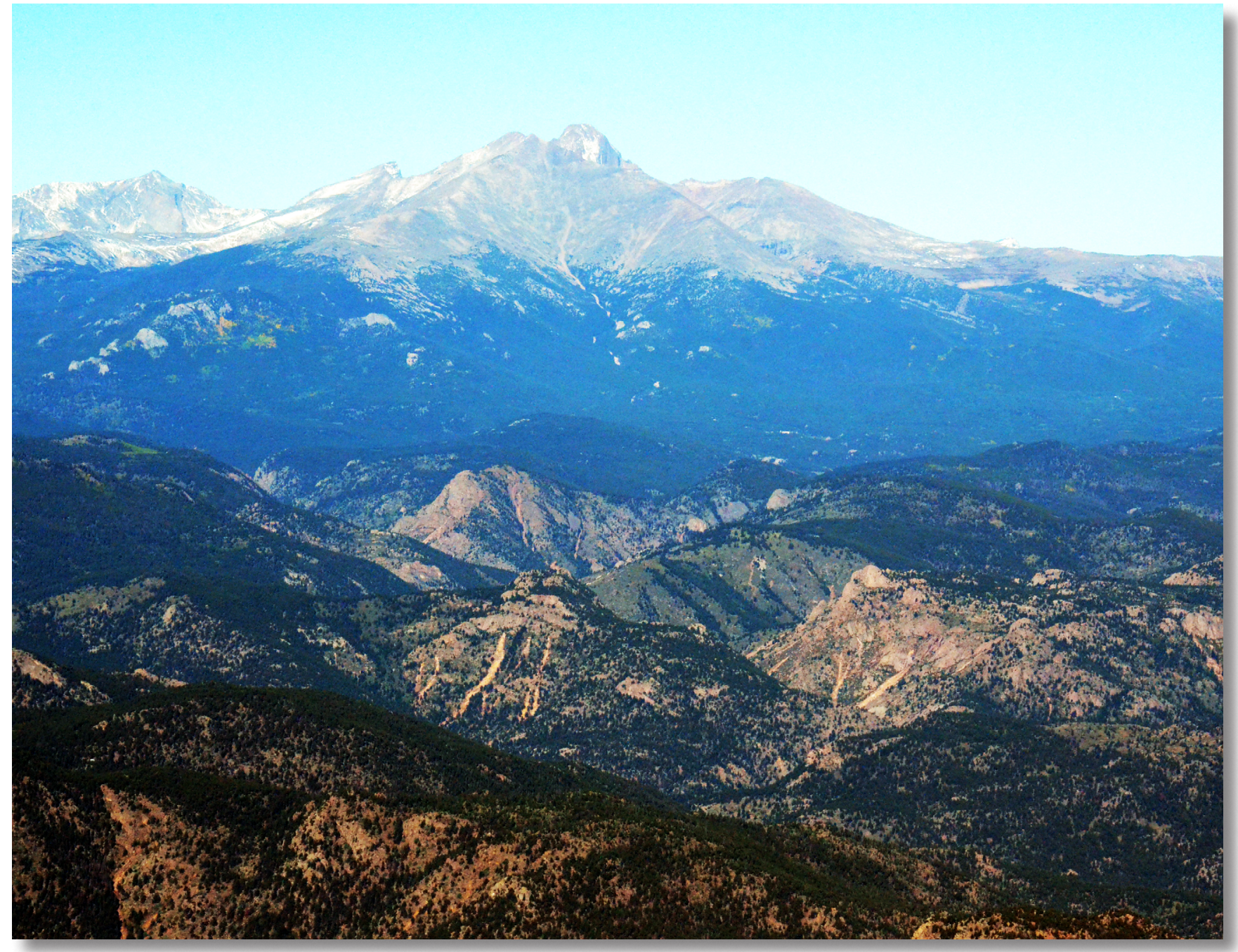

Techniques and Methods 14-A2 
Cover. Photograph from September 2013 showing recent rainfall-induced debris flows affecting Mount Meeker and the lower mountains northwest of Boulder, Colorado. Photograph by Jeff Coe, U.S. Geological Survey. 


\section{THRESH—Software for Tracking Rainfall Thresholds for Landslide and Debris-Flow Occurrence, User Manual}

By Rex L. Baum, Sarah J. Fischer, and Jacob C. Vigil

Chapter 2 of

Section A, Modeling Methods

Book 14, Landslide and Debris-Flow Assessment

Techniques and Methods 14-A2 


\title{
U.S. Department of the Interior RYAN K. ZINKE, Secretary
}

\section{U.S. Geological Survey William H. Werkheiser, Deputy Director exercising the authority of the Director}

\author{
U.S. Geological Survey, Reston, Virginia: 2018
}

For more information on the USGS — the Federal source for science about the Earth, its natural and living resources, natural hazards, and the environment-visit https://www.usgs.gov or call 1-888-ASK-USGS.

For an overview of USGS information products, including maps, imagery, and publications, visit https://store.usgs.gov.

Any use of trade, firm, or product names is for descriptive purposes only and does not imply endorsement by the U.S. Government.

Although this information product, for the most part, is in the public domain, it also may contain copyrighted materials as noted in the text. Permission to reproduce copyrighted items must be secured from the copyright owner.

Suggested citation:

Baum, R.L., Fischer, S.J., and Vigil, J.C., 2018, THRESH—Software for tracking rainfall thresholds for landslide and debris-flow occurrence, user manual: U.S. Geological Survey Techniques and Methods, book 14, chap. A2, 33 p., https://doi.org/10.3133/tm14A2.

ISSN 2328-7055 (online) 


\section{Contents}

Abstract

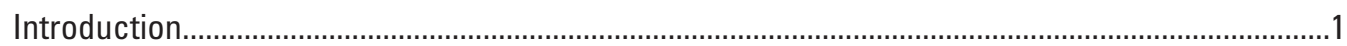

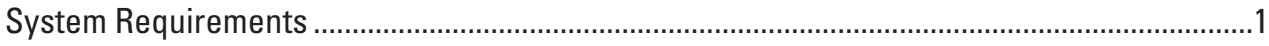

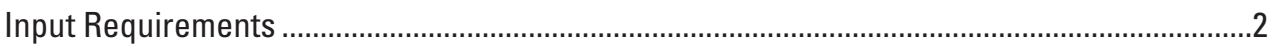

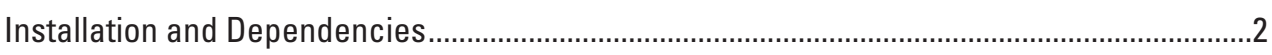

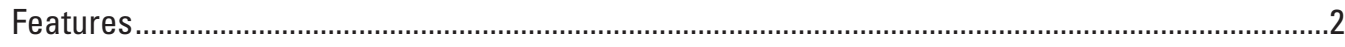

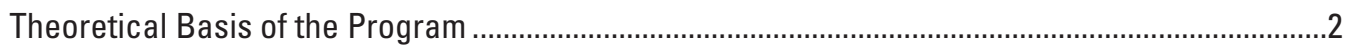

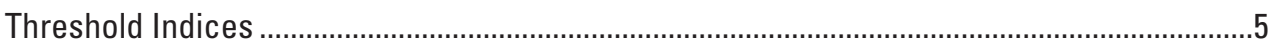

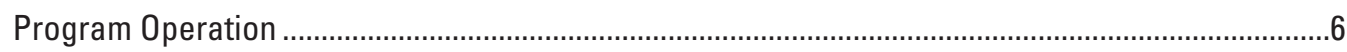

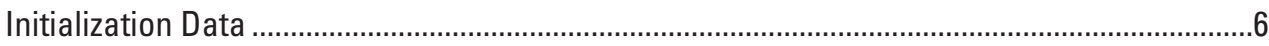

Mode and Output Options .................................................................................................

Intensity-Duration Threshold Types.........................................................................

Operating Modes and Associated Output ....................................................................

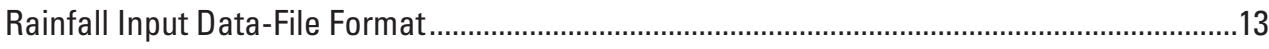

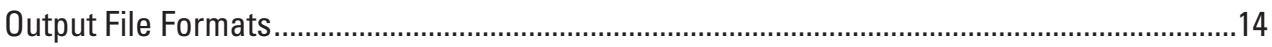

Choosing Colors for the ThCurrTabl.htm File ..............................................................16

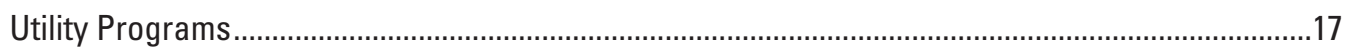

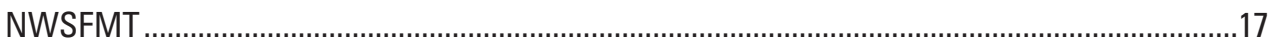

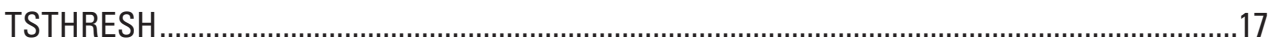

Shell Scripts and Corresponding Batch Files ...................................................................18

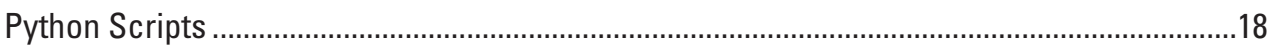

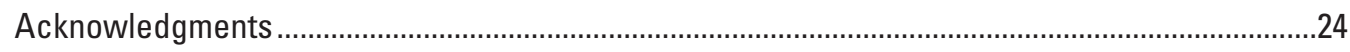

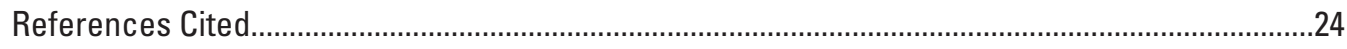

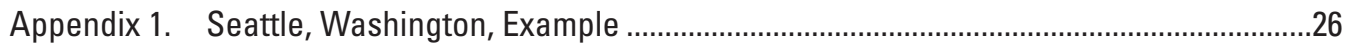

Preparing the THRESH Initialization File for an Analysis ..........................................................26

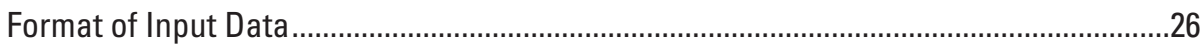

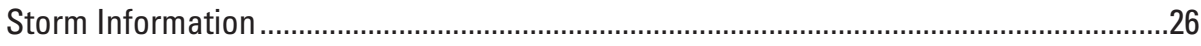

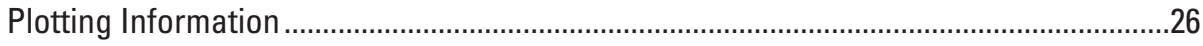

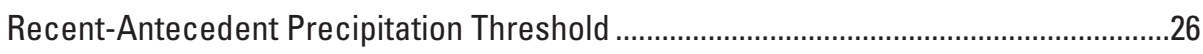

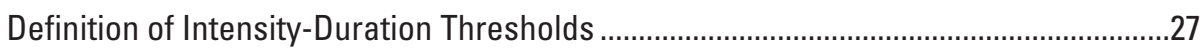

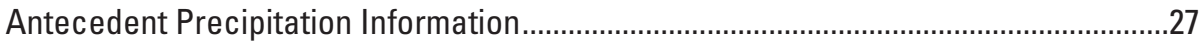

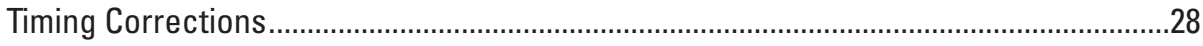

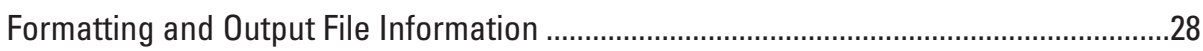

Input Data Information and Output File Path.............................................................28

Using THRESH to Analyze Precipitation Thresholds ….......................................................2

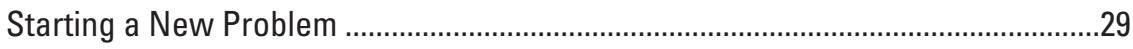

Using the Programs THRESH and NWSFMT Without the Aid of Python Scripts .............30

Starting a New Problem ...........................................................................................

Appendix 2. Example of Using Rainfall Forecasts with Thresholds ............................................32

Appendix 3. Hydrological Monitoring Sites ……………............................................................33 


\section{Figures}

1. Example input file showing the first 10 lines of file $K B F I$ t.txt in the folder LandslideThresholds/data/test/.

2. Example listing of the first few lines of ThArchive 01.txt .................................................14

3. Example of THRESH output file ThAlert.htm...................................................................15

4. Example of THRESH output file ThCurrTabl.htm .............................................................16

5. Example plot showing current conditions at four stations relative to the 3-day recent and 15-day antecedent cumulative precipitation threshold

6. Example plot showing current conditions and 15-day history of conditions at Boeing Field relative to the cumulative 3-day recent and 15-day antecedent precipitation threshold

7. Example plot of storm average intensity and duration for four weather stations where intensity is near zero for all stations

8. Example of plot showing a 15-day history of the antecedent water index for each of four weather stations

\section{Tables}

1. Listing of an example initialization file, named thresh_in.txt, for the program THRESH

2. Explanation of entries in the initialization file, thresh_in.txt, for the program THRESH.

3. Listing of output file names and descriptions. ................................................................12

4. Listing and explanation of input file Colors.txt....................................................................16

5. Listing of an example initialization file named nwsfmt_in.txt for the program NWSFMT.

6. Listing of an example initialization file named tsth_in.txt for the program TSTHRESH

7. Listing of shell scripts and corresponding Microsoft ${ }^{\circledR}$ Windows ${ }^{\circledR}$ batch files and intended purpose...

8. Listing of Python scripts with this distribution for processing and plotting data and intended purpose

1-1. Example of input file interpolatingPoints.txt. 


\section{Conversion Factors}

Inch/Pound to International System of Units

\begin{tabular}{lcl}
\hline \multicolumn{1}{c}{ Multiply } & By & \multicolumn{1}{c}{ To obtain } \\
\hline inch (in.) & Length & \\
inch (in.) & 2.54 & centimeter $(\mathrm{cm})$ \\
foot (ft) & 25.4 & millimeter (mm) \\
\hline & 0.3048 & meter (m) \\
\hline square foot $\left(\mathrm{ft}^{2}\right)$ & Area & \\
square inch $\left(\mathrm{in}^{2}\right)$ & 0.09290 & square meter $\left(\mathrm{m}^{2}\right)$ \\
\hline
\end{tabular}

Temperature in degrees Celsius $\left({ }^{\circ} \mathrm{C}\right)$ may be converted to degrees Fahrenheit $\left({ }^{\circ} \mathrm{F}\right)$ as

$$
{ }^{\circ} \mathrm{F}=\left(1.8 \times{ }^{\circ} \mathrm{C}\right)+32 \text {. }
$$

Temperature in degrees Fahrenheit $\left({ }^{\circ} \mathrm{F}\right)$ may be converted to degrees Celsius $\left({ }^{\circ} \mathrm{C}\right)$ as ${ }^{\circ} \mathrm{C}=\left({ }^{\circ} \mathrm{F}-32\right) / 1.8$.

\section{Formatting Conventions}

The computer program, THRESH, and its utility programs and scripts use parameters to control data processing operations. Parameters are user-specified values that do not change during a simulation.

In this manual, consistent fonts and styles are used to distinguish file names, parameters, constants, commands, programs (uppercase), modules, and libraries. The fonts and styles are simply an attempt to visually identify different elements; all files and file contents use standard American Standard Code for Information Interchange (ASCII) characters.

- Directories and file names, including Python scripts, shell scripts, and batch files, are typed in italic with an asterisk in front of the common extension where appropriate. The section "Program Operation" will detail the locations and naming conventions of input and output files.

- Parameter names and values, command lines in a Disk Operating System (DOS) or Unix command line window, and sample listings of input and output files are typed in Courier New font. Input parameters are listed and edited in the initialization files thresh_in.txt, tsthresh_in.txt, and nwsfmt.txt.

- Names of software libraries and modules and Unix commands are typed in italic Courier New font. 



\title{
THRESH—Software for Tracking Rainfall Thresholds for Landslide and Debris-Flow Occurrence, User Manual
}

\author{
By Rex L. Baum, Sarah J. Fischer, and Jacob C. Vigil
}

\section{Abstract}

Precipitation thresholds are used in many areas to provide early warning of precipitation-induced landslides and debris flows, and the software distribution THRESH is designed for automated tracking of precipitation, including precipitation forecasts, relative to thresholds for landslide occurrence. This software is also useful for analyzing multiyear precipitation records to compare timing of threshold exceedance with dates and times of historical landslides. This distribution includes the main program THRESH for comparing precipitation to several kinds of thresholds, two utility programs, and a small collection of Python and shell scripts to aid the automated collection and formatting of input data and the graphing and further analysis of output results. The software programs can be deployed on computing platforms that support Fortran 95, Python 2, and certain Unix commands. The software handles rainfall intensity-duration thresholds, cumulative recent-antecedent precipitation thresholds, and peak intensity thresholds as well as various measures of antecedent precipitation. Users should have predefined rainfall thresholds before running THRESH.

\section{Introduction}

The correlation between heavy or prolonged precipitation and the occurrence of landslides began to be studied in the 1970s for its potential use in landslide early warning (Campbell, 1975; Caine, 1980). Since that time, precipitation thresholds for landslide occurrence have been developed for many areas throughout the world (Guzzetti and others, 2008). The computer program, THRESH, was developed by the U.S. Geological Survey in the early 2000s for two purposes: (1) the automated tracking of precipitation conditions relative to empirical thresholds for landslide occurrence and (2) analyzing precipitation for multiyearlong periods of record to compare historical threshold exceedance to dates of historical landslides for the purpose of assessing threshold performance. Subsequently, the program has been used to track rainfall conditions relative to landslide thresholds in the Seattle, Washington, area (http://landslides.usgs.gov/monitoring/seattle/) on a nearly continuous basis since January 2006. The program was also used to analyze performance of rainfall thresholds for Seattle against historical records (Chleborad and others, $2006 ; 2008)$. The software has been used to improve precipitation thresholds for the rail corridor near Mukilteo and Everett, Washington, and to incorporate rainfall forecasts into precipitation tracking to enhance early warning for landslides (Scheevel and others, 2017).

This software distribution includes the main computer program THRESH; two utility programs: NWSFMT and TSTHRESH; and several scripts used to help automate the operation of THRESH and visualize its output. This user manual provides detailed documentation of THRESH along with brief descriptions of the utility programs and examples showing how to set up and use the software. The source code and executables are available online at https://doi.org/10.5066/F7Q23XR0.

\section{System Requirements}

THRESH has been tested on Microsoft ${ }^{\circledR}$ Windows $^{\circledR} 7$, $\operatorname{Mac}^{\circledR}$ OS $\mathrm{X}^{\circledR}$ (all versions since 10.8), and Scientific Linux (release 6.8) and should run on other computing platforms that support Fortran 90/95. The main program and all subroutines are written in Fortran 90. This distribution includes the original source code as well as executable files (Windows and Mac OS X) that can be run directly from the command line. Many of the supporting scripts are written in Python and run in version 2.7; with moderate editing, the user could get them to run under Python 3. Shell scripts (and equivalent Windows batch files) make up the remainder of the scripts. The Windows batch files also require Cygwin (Cygwin1.dll version 6.1 or later, https://cygwin.com/index.html) and a package of Unix commands that have been ported to Windows (http://unxutils.sourceforge.net/). We chose not to develop a graphical user interface because the program is usually run in batch mode. Consequently, we have provided example shell scripts and batch files that can be used to automate data processing with THRESH and integrate it with example Python scripts that demonstrate methods for data acquisition and plotting. 


\section{Input Requirements}

The software distribution includes all the information and sample data necessary to run the programs. Applying the software to any specific problem requires (1) a source or sources of continuous time-series precipitation data in hourly or shorter increments and (2) one or more predefined precipitation thresholds for landslide occurrence of a type supported by the software. These include rainfall intensity-duration (ID) thresholds, cumulative recent-and-antecedent (RA) precipitation thresholds, running-average-intensity thresholds, and peak intensity thresholds. The software was designed to use input precipitation data collected at a specific point as from rain gages. Satellite or radar data might also be usable with appropriate calibration if converted to time series for specific geographic coordinates.

\section{Installation and Dependencies}

The latest version of source code required to compile THRESH, as well as the supporting makefile, scripts, and sample data files and compiled binary executable files for selected platforms, can be downloaded from the software repository at https://doi.org/10.5066/F7Q23XR0 and at http://github.com/usgs/landslides-thresholds. First, download the archive file from the repository, extract the contents of the zip archive file to the desired location on your computer, and rename the top-level directory of the package thresh-master-*/ to LandslideThresholds/. Throughout the remainder of this report, we will assume that the threshmaster-*/ directory has been renamed and refer to it by the name LandslideThresholds/. We have provided compiled binary executable files for Mac OS X and Windows. After you have installed the LandslideThresholds/ folder, download the executables that are appropriate for your system and place them in the folder LandslideThresholds/bin/. The executable files can be accessed from the releases tab at http://github.com/usgs/landslides-thresholds/releases. Instructions for compiling the code for other systems are available in the code repository.

Python version 2 (preferably Python 2.7.10 or later), including a number of Python libraries, must be installed on the system in order to run all of the scripts. These include the following:

- Python 2.7.10 or later

- matplotlib 1.43 or later

- NumPy 1.9 .2 or later

- pandas 0.16 .2 or later

- xmI todict 0.9 .2 or later

The easiest way to obtain all of the necessary

Python libraries is to install Anaconda first

(https://www.continuum.io/downloads).
We have provided executable files for the programs THRESH, NWSFMT, and TSTHRESH on GitHub. These files are attached to the latest release at https:/github.com/ usgs/landslides-thresholds/releases. If executable files for THRESH, NWSFMT, and TSTHRESH are not available for your computer's operating system, it is necessary to compile the code - instructions are available in the source code repository, or see the README file in the folder LandslideThresholds/src/ for more information.

The batch files and some of the Python scripts provided to support automated operation rely on Unix commands; therefore, Cygwin and a package of Unix commands ported to Windows must be installed on any Windows systems intended for automated tracking of precipitation thresholds using this distribution (see LandslideThresholds/bin/unx/ README.md for more information). All of the necessary commands to support automation are already installed on Unix and Linux systems (including Mac OS X). Regardless of operating system being used, shell scripts or corresponding Windows batch files may require editing to make sure path names are compatible with your system. For information on how to run THRESH and a brief example, see appendix 1.

\section{Features}

THRESH is designed for comparing hourly or subhourly rainfall with rainfall thresholds for landslide occurrence. The program runs from the command line and uses two kinds of input files. The first is an initialization file, named thresh_in.txt, and it contains parameters defining the rainfall thresholds as well as other information needed to run the program. The second kind is a data file containing rainfall data and time and date information. The following paragraphs and tables (1) define the types of precipitation thresholds supported by the program THRESH, (2) describe the information contained in the initialization file and the format of the data files, (3) define variables and structure of THRESH, and (4) show examples of the output. Appendix 1 provides an example that shows how to set up and use the program with a sample dataset.

\section{Theoretical Basis of the Program}

Various types of rainfall thresholds for landslide occurrence began to appear in the literature in the mid-1970s (Campbell, 1975; Caine, 1980) and have been in use for landslide forecasting and early warning since the 1980s (Keefer and others, 1987). Guzzetti and others (2008) summarized the kinds of thresholds and the rainfall and climate variables used in the literature to define thresholds. They grouped empirical rainfall thresholds into three categories: (1) event-based thresholds, (2) thresholds that include antecedent precipitation, and (3) other thresholds, including hydrological thresholds. 
The computer program THRESH is designed to handle a subset of event-based and antecedent thresholds. It directly handles several of the common rainfall variables, such as duration (D), intensity (I), antecedent rainfall, and threshold types appearing in the literature (Guzzetti and others, 2008). With some adjustments or creativity on the part of the user, the program can handle a few other types as well, such as peak intensity, daily rainfall, or normalized rainfall. For example, thresholds based on rainfall normalized by mean annual precipitation can be localized by inverting the normalization.

Event-based thresholds use precipitation measurements collected during specific storms or rainfall events and include rainfall ID thresholds, total event rainfall $(E)$, rainfall event-duration (ED) thresholds, and rainfall event-intensity (EI) thresholds. ID thresholds compare the average or peak rainfall intensity or rate, $I\left[L T^{-1}\right]$, to the duration of the storm, $D[T]$, where symbols in square brackets indicate dimensions of length, $[L]$ or time, $[T]$. The total event rainfall, $E[L]$, is the cumulative rainfall amount during the storm; the program THRESH handles ID thresholds based on average intensity, $I$, for the event. ED thresholds are readily converted to ID thresholds by dividing the total event rainfall, $E$, by the event duration, $D(I=E / D)$. However, $E$ and EI thresholds are not handled by THRESH. Peak intensity, $I_{P}$, and fixed-duration intensities (running-average intensities), $I_{F D}$, can also be computed and tracked using the running-averageintensity feature of THRESH.

ID thresholds seem to be among the most widely used thresholds for landslide forecasting (Guzzetti and others, 2008). In many cases, these are defined by a power law because many ID thresholds define an approximately straight line when plotted at a logarithmic scale (Guzzetti and others, 2008).

$$
I=c D^{-b}, D_{\min } \leq D \leq D_{\max }
$$

where
$c$ is a scaling coefficient,
$b \quad$ is the exponent of the power function,
$D \quad$ is the event duration, defined as a period of continuous rainfall with no gaps
longer than a specified time interval (usually several hours) that depends on rainfall climate of a specific area (Godt and others, 2006),
$D_{\max } \quad$ is the upper duration at which the threshold is defined, and
$D_{\min }^{\max } \quad$ is the lower duration at which the threshold is defined.
Not all ID thresholds are well fitted to a power function, so the program THRESH

includes two other means for defining ID thresholds (eq. 2). One is a fifth-degree polynomial.

$$
I=I_{0}+D\left(c_{1}+D\left(c_{2}+D\left(c_{3}+D\left(c_{4}+c_{5} D\right)\right)\right)\right), D_{\min } \leq D \leq D_{\max }
$$

where

$I_{0} \quad$ is a constant intensity value, and

$c_{1}, \ldots, c_{5}$ are empirical-fitting coefficients of the polynomial.

The other method for defining the ID uses multilinear interpolation between specified points where the threshold intensity has been defined for selected durations. This latter option is available for comparing observed rainfall to thresholds that cannot be adequately described by either a power law or a polynomial.

One of the complexities of using intensity thresholds is periods of no rainfall during a storm. Whether computing intensity is based on a fixed duration, as in the case of runningaverage intensity, or total storm duration, as in the case of a storm-average, ID threshold, it is necessary to include times of no precipitation in calculating $I$ and $D$. For ID thresholds, it is customary to separate individual storms by specifying a set length of time, $T_{g a p}$, between rainstorms based on the rainfall climatology of a particular area (Godt and others, 2006). The program THRESH allows the user to specify the number of hours to be used in separating storms for intensity and duration computations. Users may specify a decimal fraction for gaps shorter than 1 hour (h) as might be needed for runoff-generated debris flows. Accounting for short periods $\left(<T_{\text {gap }}\right)$ of no rainfall during storms can be handled in various ways, and we have chosen an approach that seems most convenient to support continuous monitoring of 
precipitation relative to thresholds. Therefore, THRESH temporarily suspends incrementing $D$ when rainfall stops temporarily and resumes when rainfall resumes if the elapsed time is less than the $T_{\text {gap }}$. After the elapsed time of no rainfall exceeds $T_{g a p}, I$ and $D$ are reset to 0.0 inch per hour $(\mathrm{in} / \mathrm{h})$, or millimeter per hour $(\mathrm{mm} / \mathrm{h})$, and $0.0 \mathrm{~h}$, respectively until a new rainstorm begins. This approach is used so that total storm duration can be computed correctly but has some undesirable side effects. Users should be aware that output files will contain lines of output for $I$ and $D$ directly after a storm ends and for periods of no rainfall during storms. These are easily recognized because $D$ stays the same, and the corresponding rainfall input is $0.0 \mathrm{in}$. or $\mathrm{mm}$. Although THRESH includes code to correct these artifacts so that they do not appear in the short-term output files after a storm has ended, the artifacts will be present during a storm. Some artifacts will persist in the long-term archive files created incrementally during continuous operations because rewriting these files after each storm is inefficient.

Various measures of antecedent precipitation have been proposed in the literature, and THRESH handles a few of them. One of the most commonly used measures of antecedent precipitation in the western United States is the seasonal antecedent precipitation (SAP), which is simply the total precipitation since the beginning of the rainy season (Campbell, 1975).

When SAP exceeds a threshold amount, the soil is considered moist enough to be susceptible to landslides with additional rainfall. Some authors have used an antecedent precipitation based on a specified number of days before the event (Wieczorek and Sarmiento, 1988; Chleborad, 2003; Chleborad and others, 2008). Another more sophisticated measure of pre-event conditions is a water-balance model (Wilson and Wieczorek, 1995). The specific water-balance model available in THRESH is the antecedent water index (AWI) (Godt and others, 2006), which seeks to imitate the rise and fall of soil moisture levels resulting from precipitation, evapotranspiration, and drainage. The AWI is defined as

$$
\begin{gathered}
I=I_{0}+D\left(c_{1}+D\left(c_{2}+D\left(c_{3}+D\left(c_{4}+c_{5} D\right)\right)\right)\right), D_{\min } \leq D \leq D_{\max } \\
A W I_{t}=A W I_{t-1} e^{-k_{d} \Delta t}+\frac{I_{i}}{k_{d}}\left(1-e^{-k_{d} \Delta t}\right), A W I \geq 0
\end{gathered}
$$

where

$k_{d} \quad$ is an empirical drainage constant (Godt and others, 2006),

$\Delta t \quad$ is the time increment (commonly $1 \mathrm{~h}$ ), and

$I_{i} \quad$ is the current rainfall intensity minus the evapotranspiration rate (obtained

from published measurements, where available), and the subscripts $t$ and

$t-1$ refer to the current and previous time steps.

At the end of the summer dry season, the initial value of the AWI is set to $-C_{f}$, where $C_{f}$ is the approximate field capacity or approximate amount of water the soil column is able to hold after gravity drainage. The rainfall increments (minus evapotranspiration) are added to the AWI until it becomes positive (eq. 3). The exponential drainage terms in equation 4 are applied only after the AWI reaches 0 (zero) (Godt and others, 2006). The AWI is compared to a user-defined, location-specific threshold value to determine when the soil is likely to be wet enough to produce landslides given additional rainfall sufficient to exceed the ID (Godt and others, 2006).

Chleborad (2003) defined a threshold based on recent and antecedent precipitation totals termed the RA precipitation threshold. This threshold partitions the cumulative precipitation for a specified number of days into a recent part and an antecedent part. The general formula is a straight line defining the recent precipitation in terms of the antecedent precipitation.

$$
P_{R}=P_{A 0}+m P_{A}
$$

where

$P_{R} \quad$ is the recent precipitation total [L] for a specified period of time ending with the latest measurement, and the subscript $R$ is the number of days of recent precipitation,

$P_{A} \quad$ is the total antecedent precipitation [L] during a specified period of time ending directly before the recent period, and the subscript $A$ is the number of days of antecedent precipitation, 
$P_{A 0} \quad$ is the intercept [L] of the threshold line on the $P_{R}$ axis, equivalent to the optimum amount of $P_{R}$ (Scheevel and others, 2017), and

$m \quad$ is the slope of the threshold line.

The sum of $P_{R}$ and $P_{A}$ is the total cumulative precipitation during the last $R+A$ days. For example, if $R$ is 3 days and $A$ is 15 days, then $P_{R}+P_{A}$ is the total cumulative precipitation during the last 18 days (Chleborad and others, 2008). If tracking the RA threshold using hourly precipitation, then the recent precipitation always corresponds to the last $24 R \mathrm{~h}$ and the antecedent precipitation corresponds to the $24 A \mathrm{~h}$ immediately preceding the $24 R \mathrm{~h}$.

\section{Threshold Indices}

To simplify tracking and plotting of threshold exceedance (as a time series), we have defined a set of threshold indices. Exceedance indices for event thresholds, ID and I, are computed as the ratio of the observed intensity, $I_{o b s}$, to the threshold value at the corresponding duration. Thus, indices greater than or equal to 1 indicate threshold exceedance, and indices less than 1 indicate that the threshold has not been exceeded at a particular point in time. Two threshold exceedance indices for event thresholds have been defined in THRESH $-E_{I D}$, the index for exceedance of the ID threshold (eq. 6), defined previously (eqs. 1 and 2), and $E_{I D f}$, for exceedance of the running-average-intensity threshold (eq. 7).

$$
\begin{gathered}
E_{I D}=\frac{I_{o b s}}{c D^{-b}} \\
E_{I D, f}=\frac{I_{o b s, f}}{I_{E}}
\end{gathered}
$$

where

$I_{o b s} \quad$ is the observed storm intensity, computed by summing the rainfall increments during the event and dividing by the event duration;

$I_{o b s, f} \quad$ is the observed running average intensity, computed by summing the rainfall increments during the moving time interval of constant duration, $D_{f}$, and dividing by $D_{f}$; and

$I_{E} \quad$ is the running-average intensity threshold, a constant, based on a moving time interval of constant duration, $D_{f}$.

The denominator in equation 6 is the threshold intensity, $I$, of equation 1 . If the threshold intensity is computed using a polynomial or interpolating points, then the corresponding formulas or values for intensity are substituted into the denominator of equation 6 . The running average-intensity index, $E_{I}$ (eq. 7), can be used to check for storm-peak intensities exceeding a particular value, such as the peak 6-h intensity or peak 30 -minute intensity (Staley and others, 2013).

The exceedance index for the RA threshold is defined as a difference rather than a ratio. Consequently, this index can indicate how much additional rainfall is needed to reach the RA threshold (assuming antecedent rainfall amount holds steady).

$$
D_{R A}=P_{R, o b s}-P_{R}
$$

where

$D_{R A} \quad$ is the rainfall deficit below the threshold (if negative) or rainfall surplus above the threshold (if positive),

$P_{R, o b s} \quad$ is the sum of the observed rainfall during last $24 R \mathrm{~h}$, where $R$ is the number of days of recent precipitation, and

$P_{R} \quad$ is the threshold value of recent rainfall, as shown in equation 5. 


\section{Program Operation}

Upon startup, THRESH starts a log file, ThreshLog.txt, and checks the system time before reading the initialization file, thresh_in.txt (table 1). The program THRESH uses parameters obtained from the initialization file to set various conditions and identify the location of input data. It also checks the file Thlast.txt for the date and time of last data processed from each input file to avoid repeating work that was already completed. Next, THRESH opens and reads the data files and confirms that the files contain previously unprocessed data before proceeding to analyze the input data. Analysis consists of computing running sums for cumulative thresholds and running-average intensities and storm intensity and duration during periods of precipitation. If threshold exceedance statistics are desired, then exceedance events are counted for various thresholds. After computations are completed, the results are saved to an assortment of output files. Further details in the form of a detailed algorithm in pseudocode, and tables listing external procedures and variable names used by THRESH are available in the folder LandslideThresholds/doc/.

\section{Initialization Data}

The initialization file, thresh_in.txt, is formatted as comma-delimited text (table 1). An example listing of the file appears in the second column of table 1; line numbers are shown in the first (left) column for convenience in describing the content. Each line of data contains the text identifier followed by one or more numeric, logical, or character strings containing the input data. Table 2 contains a detailed explanation (right column) for each entry in the initialization file (left column), including identification of data type and range of values corresponding to each entry. All entries are required and must appear in the order listed. For character data (text), note the maximum lengths in the column under "Type"; for example, "len=2" indicates that the input for that line may be no longer than two characters.

The initialization file can be classified into several parts. In the following discussion for table 1, station (table 1, line 1) refers to an individual rain gage or weather station. Lines 1-4 contain station-dependent parameters that THRESH uses to allocate arrays and control processing. Lines 4-9 contain location-specific data used to determine durations used to sum rainfall input for tracking conditions relative to various thresholds. Lines 10-12 control the size of data gaps the user is willing to tolerate and the number of lines in two sets of output files for plotting time series results. Lines 13-24 contain parameters related to the RA threshold (lines 13-14) and the ID threshold (lines 15-23) with the units for both in line 24 . Lines 25-31 contain parameters used by various methods to account for antecedent precipitation, including the SAP and the AWI described previously. In the event that insufficient data are specified to define either, then THRESH will compute the cumulative annual precipitation, a running sum of precipitation for each calendar year. Lines 32-37 control aspects of program operation, including input dependent time conventions (lines 32-34), and output file type (line 35). Lines 36-37 determine the operating modes, which are described in more detail later, and lines 38-43 govern the output and input locations. Table 2 and the examples in appendix 1 provide additional details to help the user configure the program for various situations.

\section{Mode and Output Options}

The program THRESH provides a few options related to its operation modes. Understanding these options and how to specify them in the initialization file will help the user achieve the desired results from THRESH. This section briefly describes some of the options for controlling how the program works and the output types associated with different modes. These options include how the program defines and processes ID thresholds and whether it will be used in tracking conditions relative to thresholds or analyzing a long-term dataset to evaluate threshold performance.

\section{Intensity-Duration Threshold Types}

THRESH offers the user three options for defining the ID threshold used for calculations. Choices include a power function, a fifth-degree polynomial, or a multipoint linear interpolation (table 2). Use of a power function is the preferred method, but the other two are available if needed. The user may denote the chosen method by entering . TRUE . next to the designated method and entering . FALSE . next to the two rejected methods. For example, in table 1, a power function has been selected (lines 15, 19, and 22). Selecting the multipoint interpolation method requires use of an additional input file named interpolatingPoints.txt (see appendix 1 for more information about defining ID thresholds, including information about the required format and location of the file interpolatingPoints.txt). In the event that an ID threshold does not exist for your area of interest, you may want to use one of the worldwide thresholds (Caine, 1980; Guzzetti and others, 2008).

\section{Operating Modes and Associated Output}

The program has three operating modes: (1) continuous, (2) forecast, and (3) statistical. The default mode, continuous, is selected by typing . FALSE . on the lines labeled Statistics? and Forecast? (See lines 36 and 37 in table 1). The continuous mode runs in near real time, performs the basic threshold tracking functions, and produces a series of output files for saving results and plotting current and recent conditions (table 3 ). 
Table 1. Listing of an example initialization file, named thresh_in.txt, for the program THRESH.

[in, inch; RA, recent-antecedent; m, meter; AWI, antecedent water index] This is a plain-text representation of the initialization file without any formatting conventions.

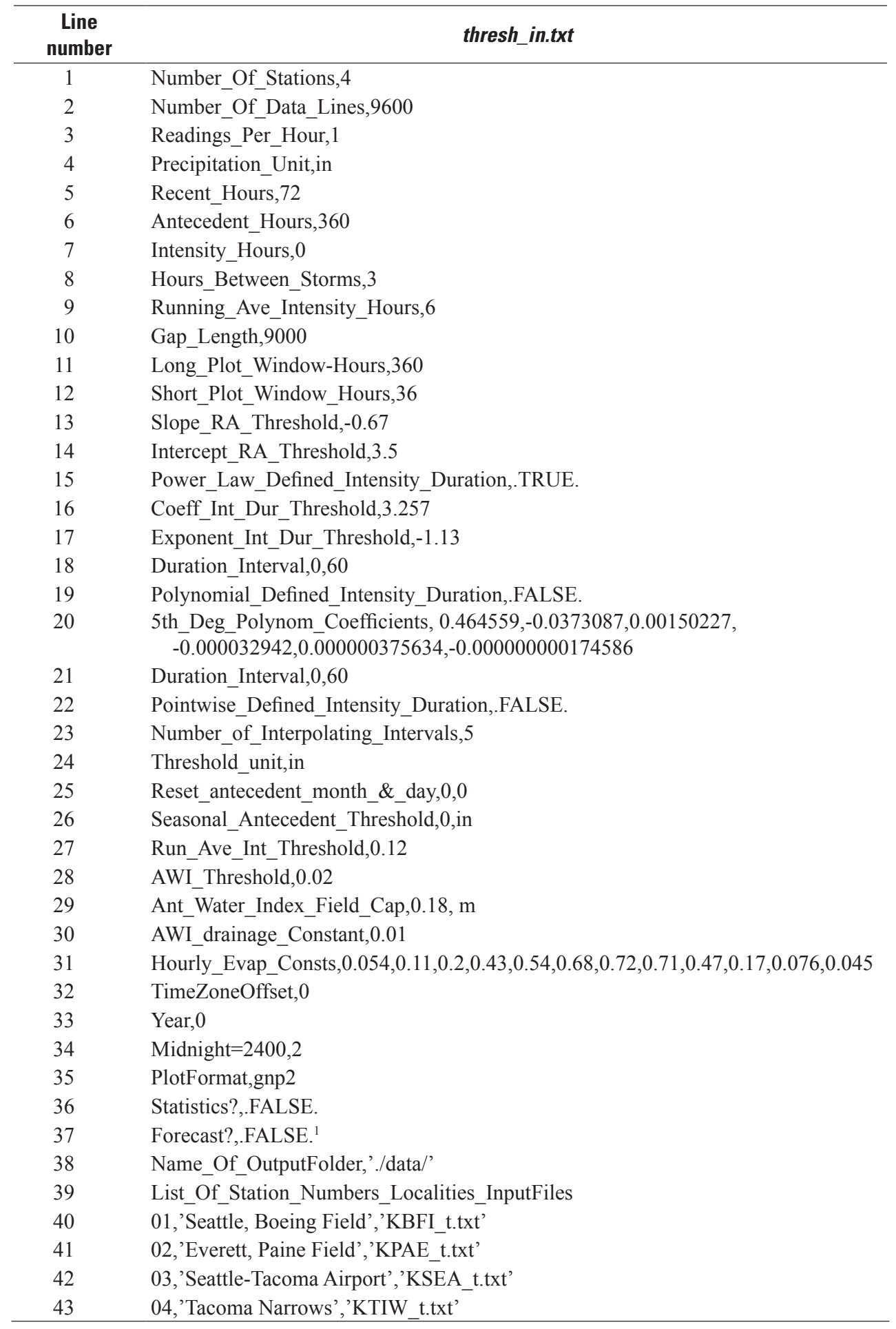

${ }^{1}$ Note that if Forecast? is . TRUE., Statistics? must be . FALSE. 
Table 2. Explanation of entries in the initialization file, thresh_in.txt, for the program THRESH.

[>, greater than; $\geq$, greater than or equal to; $<$, less than; $\leq$, less than or equal to; eq., equation; in, inch; mm, millimeter; RA, recent-antecedent; ID, intensityduration; len, length; SAP, seasonal antecedent precipitation; AWI, antecedent water index; ET, evapotranspiration; $C_{f}$, field capacity; $k_{d}$, empirical drainage constant. Directories and file names are typed in italic. Parameter names and values, command lines in a Disk Operating System (DOS) or Unix command line window, and sample listings of input and output files are typed in Courier New font]

\begin{tabular}{|c|c|c|c|}
\hline Descriptor & Type & Range & Explanation \\
\hline \multicolumn{4}{|c|}{ Format of input data } \\
\hline Number_of_Stations & Integer & $1-99$ & $\begin{array}{l}\text { Number of rainfall stations to be analyzed; a } \\
\text { separate input data file for each station must } \\
\text { be listed at the end of the initialization file. }\end{array}$ \\
\hline Number_of_Data_Lines & Integer & $>1$ & $\begin{array}{l}\text { Maximum number of lines of data appearing in } \\
\text { any of the data files; used to set array lengths } \\
\text { for time-series data; small values automati- } \\
\text { cally reset to default, } 8,784 \text { (=366x } 24) \text {. }\end{array}$ \\
\hline Readings_Per_Hour & Integer & $1-60$ & $\begin{array}{l}\text { Number of times per hour that rainfall data are } \\
\text { recorded; for example, enter } 1 \text { for hourly data } \\
\text { and } 4 \text { for } 15 \text {-minute data. }\end{array}$ \\
\hline Precipitation_Unit & Character $($ len=2) & in, $\mathrm{mm}$ & $\begin{array}{l}\text { Units of precipitation in input data files must be } \\
\text { inches or millimeters. }\end{array}$ \\
\hline Antecedent_Hours & Integer & $\geq 0$ & $\begin{array}{l}\text { Determines the number of hours of data for } \\
\text { computing the antecedent rainfall for the RA } \\
\text { precipitation threshold ( } 24 A \text { hours, eq. } 5 \text { ); may } \\
\text { be } 0 \text { (zero) for simple, cumulative thresholds. }\end{array}$ \\
\hline Intensity_Hours & Real & $\geq 0$ & $\begin{array}{l}\text { Determines number of hours used in computing a } \\
\text { running-average intensity, such as a 6-h average } \\
\text { intensity; default value, } 0 \text {, results in computing } \\
\text { storm-average intensity for ID threshold. }\end{array}$ \\
\hline Hours_Between_Storms & Real & $>0$ & $\begin{array}{l}\text { Determines the number of hours of no rainfall } \\
\text { needed to separate storms when computing the } \\
\text { ID threshold. }\end{array}$ \\
\hline Long_Plot_Window_Hours & Integer & $>1$ & $\begin{array}{l}\text { Number of rows of time-series output values } \\
\text { saved to a text file, ThTSPlotHHHhrSS.txt } \\
\text { (table 3), formatted for use by plotting } \\
\text { routines. }\end{array}$ \\
\hline Short_Plot_Window_Hours & Integer & $>1$ & $\begin{array}{l}\text { Number of rows of time-series output } \\
\text { values saved to a second text file, } \\
\text { ThTSPlotHHHhrSS.txt (table 3), formatted for } \\
\text { use by plotting routines. }\end{array}$ \\
\hline
\end{tabular}


Table 2. Explanation of entries in the initialization file, thresh_in.txt, for the program THRESH._-Continued

[>, greater than; $\geq$, greater than or equal to; $<$, less than; $\leq$, less than or equal to; eq., equation; in, inch; mm, millimeter; RA, recent-antecedent; ID, intensityduration; len, length; SAP, seasonal antecedent precipitation; AWI, antecedent water index; ET, evapotranspiration; $C_{f}$, field capacity; $k_{d}$, empirical drainage constant. Directories and file names are typed in italic. Parameter names and values, command lines in a Disk Operating System (DOS) or Unix command line window, and sample listings of input and output files are typed in Courier New font]

\begin{tabular}{|c|c|c|c|}
\hline Descriptor & Type & Range & Explanation \\
\hline \multicolumn{4}{|c|}{ RA precipitation threshold parameters } \\
\hline Slope_RA_Threshold & Real & $\leq 0$ & $\begin{array}{l}\text { Slope used in defining the RA precipitation } \\
\text { threshold; may be negative or } 0 \text { (zero) for } \\
\text { simple cumulative thresholds. }\end{array}$ \\
\hline Intercept_RA_Threshold & Real & $\geq 0$ & $\begin{array}{l}\text { Intercept used in defining the RA precipitation } \\
\text { threshold. }\end{array}$ \\
\hline Power_Law_Defined_Intensity_Duration & Logical & $\begin{array}{l}\text {.TRUE., } \\
\text {. FALSE. }\end{array}$ & $\begin{array}{l}\text { Used to determine whether the power law will be } \\
\text { chosen to calculate ID thresholds. }\end{array}$ \\
\hline Coeff_Int_Dur_Threshold & Real & $>0$ & $\begin{array}{l}\text { Coefficient used in defining a power function for } \\
\text { the ID threshold (eq. 1). }\end{array}$ \\
\hline Exponent_Int_Dur_Threshold & Real & $<0$ & $\begin{array}{l}\text { Exponent used in defining power function for the } \\
\text { ID threshold (eq. 1). }\end{array}$ \\
\hline Duration_Interval & Real & $\geq 0$ & $\begin{array}{l}\text { Determines the lower and upper duration limits } \\
\text { (hours) for ID thresholds (if the power law is } \\
\text { used). }\end{array}$ \\
\hline $\begin{array}{l}\text { Polynomial_Defined_Intensity_ } \\
\quad \text { Duration }\end{array}$ & Logical & $\begin{array}{l}\text {. TRUE. } \\
\text {. FALSE. }\end{array}$ & $\begin{array}{l}\text { Used to determine whether the ID thresholds will } \\
\text { be defined by a fifth-degree polynomial. }\end{array}$ \\
\hline 5th_Deg_Polynom_Coefficients & Real & $\begin{array}{l}\text { Any real } \\
\text { number }\end{array}$ & $\begin{array}{l}\text { Coefficients of the fifth-degree polynomial (in } \\
\text { order of increasing power, eq. 2) used to } \\
\text { represent ID thresholds that are not adequately } \\
\text { modeled by a power function. }\end{array}$ \\
\hline Duration Interval & Real & $\geq 0$ & $\begin{array}{l}\text { Determines the lower and upper limits for ID } \\
\text { thresholds (if a polynomial is used). }\end{array}$ \\
\hline Pointwise_Defined_Intensity_Duration & Logical & $\begin{array}{l}\text {. TRUE. } \\
\text {. FALSE. }\end{array}$ & $\begin{array}{l}\text { Used to determine whether the ID thresholds will } \\
\text { be defined by linearly interpolating points. }\end{array}$ \\
\hline Number_of_Interpolating_Intervals & Integer & $0-100$ & $\begin{array}{l}\text { The number of linear interpolating intervals, } \mathrm{N} \text {, } \\
\text { chosen by the user (note, requires } \mathrm{N}+1 \text { inter- } \\
\text { polating points). }\end{array}$ \\
\hline Threshold_unit & Character $($ len=2) & in, $\mathrm{mm}$ & $\begin{array}{l}\text { Precipitation depth units used to define the ID } \\
\text { and RA thresholds, used for making unit con- } \\
\text { versions if, for example, precipitation input is } \\
\text { in inches and threshold defined in millimeters. }\end{array}$ \\
\hline
\end{tabular}


Table 2. Explanation of entries in the initialization file, thresh_in.txt, for the program THRESH._Continued

[ $>$, greater than; $\geq$, greater than or equal to; $<$, less than; $\leq$, less than or equal to; eq., equation; in, inch; mm, millimeter; RA, recent-antecedent; ID, intensityduration; len, length; SAP, seasonal antecedent precipitation; AWI, antecedent water index; ET, evapotranspiration; $C_{f}$, field capacity; $k_{d}$, empirical drainage constant. Directories and file names are typed in italic. Parameter names and values, command lines in a Disk Operating System (DOS) or Unix command line window, and sample listings of input and output files are typed in Courier New font]

\begin{tabular}{|c|c|c|c|}
\hline Descriptor & Type & Range & Explanation \\
\hline \multicolumn{4}{|c|}{ Antecedent precipitation information } \\
\hline Reset_antecedent_month_\&_day & Integer, integer & $\begin{array}{l}0-12 \\
0-31\end{array}$ & $\begin{array}{l}\text { The day and month to start annual antecedent } \\
\text { rainfall running total; } 0,0 \text { disables seasonal } \\
\text { antecedent in favor of AWI. }\end{array}$ \\
\hline Seasonal_Antecedent_Threshold & $\begin{array}{l}\text { Real, character } \\
\quad(\text { len }=2)\end{array}$ & $\geq 0$ in, $\mathrm{mm}$ & $\begin{array}{l}\text { The value chosen for the SAP threshold and its } \\
\text { length units (inch, millimeter). }\end{array}$ \\
\hline AWI_Threshold & Real & $>-C_{f}$ & Threshold value for AWI in same units as $C_{f}$. \\
\hline Ant_Water_Index_Field_Cap & Real, character & $>0 \mathrm{ft}, \mathrm{m}$ & $\begin{array}{l}C_{f} \text { of soil and length unit (feet, meters) used in } \\
\text { computing the AWI. }\end{array}$ \\
\hline AWI_drainage_Constant & Real & $\geq 0$ & $\begin{array}{l}k_{d} \text {, in units compatible with } C_{f} \text {, used in comput- } \\
\quad \text { ing the AWI. }\end{array}$ \\
\hline \multicolumn{4}{|c|}{ Timing corrections } \\
\hline TimeZoneoffset & Integer & $-23-23$ & $\begin{array}{l}\text { Difference in number of hours between the time } \\
\text { zone of the computer performing computa- } \\
\text { tions (or Coordinated Universal Time [UTC]) } \\
\text { and the area of observation; may be } 0 \text { (zero) in } \\
\text { statistics mode. }\end{array}$ \\
\hline
\end{tabular}


Table 2. Explanation of entries in the initialization file, thresh_in.txt, for the program THRESH._Continued

[>, greater than; $\geq$, greater than or equal to; $<$, less than; $\leq$, less than or equal to; eq., equation; in, inch; mm, millimeter; RA, recent-antecedent; ID, intensityduration; len, length; SAP, seasonal antecedent precipitation; AWI, antecedent water index; ET, evapotranspiration; $C_{f}$, field capacity; $k_{d}$, empirical drainage constant. Directories and file names are typed in italic. Parameter names and values, command lines in a Disk Operating System (DOS) or Unix command line window, and sample listings of input and output files are typed in Courier New font]

\begin{tabular}{|c|c|c|c|}
\hline Descriptor & Type & Range & Explanation \\
\hline \multicolumn{4}{|c|}{ Formatting and output information } \\
\hline PlotFormat & Character $($ len $=4)$ & $\begin{array}{l}\text { gnp1, } \\
\text { gnp2, } \\
\text { dgrs }\end{array}$ & $\begin{array}{l}\text { Plot file formats are ASCII text; the different } \\
\text { options are suited to various plotting rou- } \\
\text { tines in common use. The choices are gnp1, } \\
\text { gnp2, and dgrs; all contain only the latest } \\
\text { computations in tab-delimited text format. } \\
\text { Option gnp1 saves recent and antecedent } \\
\text { totals, intensity, duration, and related outputs } \\
\text { with all stations in a single output file. Option } \\
\text { gnp2 saves the same output as gnp1 but with } \\
\text { output for each station going to a separate file. } \\
\text { Option dgrs saves recent and antecedent totals } \\
\text { only to a single output file as tab-delimited } \\
\text { text. See "Output File Formats" for further } \\
\text { information. }\end{array}$ \\
\hline Forecast? & Logical & $\begin{array}{l}\text {. TRUE . } \\
\text {. FALSE . }\end{array}$ & $\begin{array}{l}\text { Used to determine if the input data provided is a } \\
\text { forecast or current. If forecast is .TRUE., then } \\
\text { statistics must be set to .FALSE. See "Operat- } \\
\text { ing Modes and Associated Output" for more } \\
\text { information. }\end{array}$ \\
\hline
\end{tabular}

\begin{tabular}{|c|c|c|c|}
\hline \multicolumn{4}{|c|}{ Output file path and input file information } \\
\hline Name_Of_OutputFolder & Character $($ len=255) & $\begin{array}{l}\text { Any valid } \\
\text { directory } \\
\text { name }\end{array}$ & $\begin{array}{l}\text { Path name of the folder where output files are to } \\
\text { be placed; absolute or relative paths up to } 255 \\
\text { characters long may be used. Final character } \\
\text { must be "/" (Unix/Linux) or "I" (Windows); } \\
\text { for best results, put path name between quotes. }\end{array}$ \\
\hline \multirow[t]{2}{*}{$\begin{array}{l}\text { ListofStationNumbers_Localities_ } \\
\text { InputFiles }\end{array}$} & Character $($ len $=31)$ & $\begin{array}{l}\text { Any valid } \\
\text { text }\end{array}$ & $\begin{array}{l}\text { Descriptive heading for list of station numbers, } \\
\text { station names, and data input files on succeed- } \\
\text { ing lines. }\end{array}$ \\
\hline & $\begin{array}{l}\text { Integer array, } \\
\text { Character array } \\
(\text { len }=50), \text { Character } \\
\text { array }(\text { len }=255)\end{array}$ & $\begin{array}{l}00-99 \text { Any } \\
\text { valid text } \\
\text { Any valid } \\
\text { path name }\end{array}$ & $\begin{array}{l}\text { Station number, station name or location, and } \\
\text { path name of corresponding data file; this pat- } \\
\text { tern is repeated on each succeeding line for the } \\
\text { remaining rainfall stations. Use the last two } \\
\text { digits of the National Weather Service station } \\
\text { number. Station numbers are not required to } \\
\text { be in numerical order. The station name can } \\
\text { be either a formal name or if none exists, a } \\
\text { descriptive name based on location. File path } \\
\text { names can be either full or relative depend- } \\
\text { ing on their relation to the present working } \\
\text { directory. }\end{array}$ \\
\hline
\end{tabular}


Table 3. Listing of output file names and descriptions.

[fig., figure; eq., equation; RA, recent-antecedent; ID, intensity-duration; AWI, antecedent water index; SS two-digit station number appearing in file names; $H H H$, three-digit number of hours appearing in file names and designating the length of the time series contained in the file; $D_{R A}$, the RA threshold exceedance index; $D$, storm duration; $E_{I D, f}$, running-average rainfall intensity exceedance index; underline emphasizes the different thresholds or threshold combinations output to the file. Directories and file names are typed in italic. Parameter names and values, command lines in a Disk Operating System (DOS) or Unix command line window, and sample listings of input and output files are typed in Courier New font]

\begin{tabular}{|c|c|}
\hline Output file name & Description \\
\hline ThAlert.htm & $\begin{array}{l}\text { Threshold interpretations arranged in a table on an hypertext markup language (HTML) page that are color-coded } \\
\text { based on the severity of the alert level for conditions relative to three different thresholds (fig. } 3 \text { ). }\end{array}$ \\
\hline ThAlert.txt & $\begin{array}{l}\text { Threshold data arranged in a table in plain-text format; contains the same information as ThAlert.htm without } \\
\text { color codes. }\end{array}$ \\
\hline ThreshLog.txt & $\begin{array}{l}\text { Log file that records the date and time, contents of initialization file, and information about errors and completion } \\
\text { of various tasks by the program. This file is saved to the working directory (usually the same directory as the } \\
\text { file thresh_in.txt.). }\end{array}$ \\
\hline ThTSplotHHHhrSS.txt ${ }^{1}$ & $\begin{array}{l}\text { A pair of tab-delimited text files that contain a time-series listing for each station, designated by station number } \\
\text { SS. The length of time covered by the files is determined by the parameters Long_Plot_Window_Hours, } \\
\text { and Short_Plot_Window_Hours and is represented in the file name by HHH. Output columns include } \\
\text { time stamp, hourly precipitation, antecedent precipitation, recent precipitation, storm average intensity, storm } \\
\text { duration, base-10 logarithm of intensities, running-average intensity, RA index, ID index, running-average- } \\
\text { intensity index, and AWI. These files are used to generate time-series plots for the most recent readings. }\end{array}$ \\
\hline ThStaSS.txt & $\begin{array}{l}\text { Tab-delimited text files generated for each station, designated by station number SS, only when } \\
\text { Plot Format=gnp2 (see table 2). Outputs include antecedent precipitation, recent precipitation, storm- } \\
\text { average intensity, duration, running-average intensity, and base-10 logarithm of average intensity. }\end{array}$ \\
\hline ThUpdate.txt & $\begin{array}{l}\text { Displays the last date and time when data was updated for all stations listed in the initialization file for use in } \\
\text { labeling plots. }\end{array}$ \\
\hline \multicolumn{2}{|r|}{ Output files created or updated only in continuous or statistical modes (forecast?=. FALSE.) } \\
\hline ThArchiveSS.txt ${ }^{1}$ & $\begin{array}{l}\text { Time-series archive file for each station, designated by station number } S S \text {, in tab-delimited text format with the } \\
\text { following entries: time stamp, hourly precipitation, antecedent precipitation, recent precipitation, storm average } \\
\text { intensity, storm duration, running-average intensity, and the AWI. }\end{array}$ \\
\hline ThCurrTabl.txt & Threshold data arranged in a plain-text table that contains the same entries as ThCurrTabl.htm. \\
\hline
\end{tabular}


Table 3. Listing of output file names and descriptions.-Continued

[fig., figure; eq., equation; RA, recent-antecedent; ID, intensity-duration; AWI, antecedent water index; SS two-digit station number appearing in file names; $H H H$, three-digit number of hours appearing in file names and designating the length of the time series contained in the file; $D_{R A}$, the RA threshold exceedance index; $D$, storm duration; $E_{I D, f}$, running-average rainfall intensity exceedance index; underline emphasizes the different thresholds or threshold combinations output to the file. Directories and file names are typed in italic. Parameter names and values, command lines in a Disk Operating System (DOS) or Unix command line window, and sample listings of input and output files are typed in Courier New font]

\begin{tabular}{|c|c|}
\hline Output file name & Description \\
\hline ThTimeExID_SS.txt & $\begin{array}{l}\text { Times of exceedance for ID threshold for each station; the output columns include time stamp, hourly precipita- } \\
\text { tion, antecedent and recent precipitation, storm intensity, duration, base-10 logarithm of the storm intensity, } \\
\text { running-average intensity, RA index, ID index, running-average-intensity index, AWI, and duration description. }\end{array}$ \\
\hline ThTimExIDASS.txt & $\begin{array}{l}\text { Times of combined exceedance of the ID threshold and AWI (IDA); the file contains the same columns as pro- } \\
\text { vided in ThTimeExID_txt files. }\end{array}$ \\
\hline ThTimeExIRASS.txt & $\begin{array}{l}\text { Times of combined exceedance of the running-average-intensity and RA precipitation thresholds (IRA); the file } \\
\text { contains the same columns as provided in ThTimeExID_.txt files. }\end{array}$ \\
\hline ThTimeExRA_SS.txt & $\begin{array}{l}\text { Times of exceedance of the RA precipitation threshold; the file contains the same columns as provided in } \\
\text { ThTimeExID_txt files. }\end{array}$ \\
\hline
\end{tabular}

${ }^{1} \mathrm{SS}$ denotes two-digit station number, and HHH denotes the number of hours of time-series outputs in the file.

The second operating mode, forecast, also runs in near real time and enables combining precipitation gage data with a precipitation forecast. To enable forecast mode, enter . TRUE. next to the line labeled Forecast? and. FALSE. next to the Statistics? line. In addition to the continuous precipitation input data, the program requires quantitative precipitation forecast input data. We have implemented the automated download and parsing of hourly precipitation observations and forecast data in two Python scripts (NWS.py and Forecast.py) described in the "Python Scripts" section of this user manual. The forecast operating mode is very similar to the continuous mode except that the program will not create archive files (ThArchiveSS.txt) or the current conditions table (ThCurrTabl.htm) described in table 3. All other output files available for the continuous mode are generated in forecast mode.

The statistical mode provides statistics on threshold exceedance for the study of long-term performance of precipitation thresholds. If the user enters . TRUE. next to the line labeled Statistics? and .FALSE. next to Forecast?, several additional output files will be provided. These include files containing information on times of exceedance for rainfall thresholds based on ID, RA, intensity and cumulative precipitation, and combined exceedance of ID and AWI. In addition to this, a file containing the maximum daily values above the thresholds will be given and exceedance counts will be written to the log file, ThreshLog.txt. This option is intended to be used in a study with a long period of historical data for the purpose of comparing landslide occurrence data to threshold exceedance. This option will automatically check input files for nonsequential values (dates out of order). In the event nonsequential values are found, the program, THRESH, will notify the user and stop operation so the offending data files can be edited before proceeding with analysis.

\section{Rainfall Input Data-File Format}

The input data file format for THRESH is ASCII text with fixed-width fields (fig. 1). The first few lines of an example of an input file are shown in figure 1. The fields are defined as follows: SSYYYYMMDDHHPPP, where SS is the station number (01 in fig. 1), YYYY is the year (2010 in fig. 1), MM is the month (07 in fig. 1), DD is the day (24 in fig. 1), $\mathrm{HH}$ is the hour (ranges from 00 to 09 in fig. 1), and PPP (or PPPP) is the precipitation (000 for all rows in fig. 1). Each field is treated as an integer value. Note that the rows of data are arranged chronologically with the oldest at the top and the newest at the bottom (end of the file). The program THRESH can also read some variations on this format. The year field can be omitted, and a two-character-wide field for minutes, TT, can be added between the hour field and the precipitation field (note that Readings Per Hour, the fourth entry in the initialization file thresh_in.txt must have a value greater than 1 for this option to work). Acceptable units for precipitation input are inches and millimeters (table 2). For rain gages where precipitation is recorded in inches, the precipitation field indicates rainfall in hundredths of an inch. For example, 
if the entry in the precipitation field is 143 , it corresponds to 1.43 in. of precipitation. Similarly, for millimeter rainfall input, the precipitation field indicates precipitation in tenths of a millimeter so that 157 corresponds to $15.7 \mathrm{~mm}$.

\section{0}

012010072401000

012010072402000

012010072403000

012010072404000

012010072405000

012010072406000

012010072407000

012010072408000

012010072409000

Figure 1. Example input file showing the first 10 lines of file KBFI_t.txt in the folder LandslideThresholds/data/test/.

This file format is different than that used by the National Weather Service and most other agencies that record hourly rainfall data. The auxiliary program NWSFMT is included in this distribution for converting National Weather Service data and several other formats to the format required by THRESH. NWSFMT also runs from the command line and uses a simple initialization file to identify inputs and outputs.

\section{Output File Formats}

Upon completion, THRESH will provide several output files that contain results of the computations. In addition, THRESH will provide a log file (ThreshLog.txt) that contains a copy of the original initialization file, information about the program operation, and reporting of errors. Note that the $\log$ file is saved to the directory where the initialization file is located; all other output files are saved to the output folder (see NameOfOutputFolder, table 2). Table 3 contains a complete listing of the output files and what each provides to the user. Some files are created based on the inputs chosen by the user in the initialization file, as described previously. Most output files are in the form of tab-delimited text. Headings at the top of most files describe the contents of the file and each column of data in the file. Leading hash marks (\#) identify descriptive headings of the output files. Figure 2 shows an example of the first few lines of a typical output file (ThArchiveSS.txt). Two output files are hypertext markup language (HTML) tables for display of current conditions, and examples are shown in figures 3 and 4.

Output files contain some or all of the following columns of data:

- Time stamp indicating the date and time of the latest precipitation measurements used in computing quantities listed in the same row

- Hourly precipitation extracted directly from the input file(s) and converted to appropriate units

- Antecedent precipitation total for the number of hours specified by the parameter Antecedent_Hours and offset from the latest time by the parameter Recent_Hours (tables 1 and 2)

- Recent precipitation total for the number of hours specified by the parameter Recent_Hours

$$
\begin{aligned}
& \text { \# Archive of Rainfall Totals for Comparison with Thresholds } \\
& \text { \# Station } 01 . \text { txt } \\
& \text { \# Time and date Hourly precip. 360-h antecedent precip. } \quad \text { 72-h precip. } \\
& \text { Intensity Duration 6-h intensity Antecedent water index }
\end{aligned}
$$

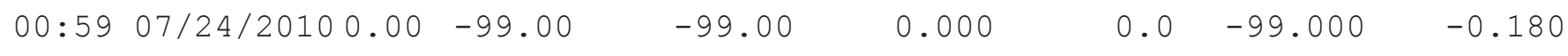

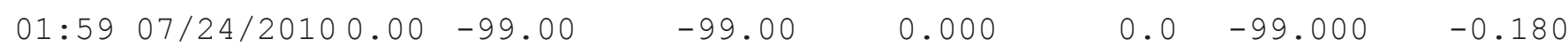

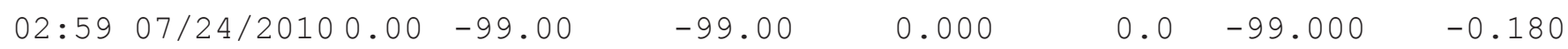

Figure 2. Example listing of the first few lines of ThArchive01.txt. The second heading line identifies the source of input data. Note that the column headings (third line, wrapped for display here) occupy a single line. Other output files of time-series data have a similar appearance but may have additional columns (table 3). The columns are separated by nonprinting tab characters. The value -99.00 or -99.000 is a placeholder for no data. In this case the no-data values appear because the elapsed time is not sufficient for computing the 72-hour cumulative precipitation, 360-hour antecedent precipitation, and 6-hour precipitation intensity. h, hours. 
- Storm intensity, (eq. 6) $I_{o b s}$, or a running-average intensity, (eq. 7) $I_{o b s, f}$, depending on the specified value of the parameter Intensity_Hours

- Storm duration, (eqs. 1 and 2) $D$

- Running-average intensity, (eq. 7) $I_{o b s, f}$, for the number of hours specified by the parameter Running_Ave Intensity_Hours, which corresponds to (eq. 7) $\bar{D}_{f}$

- AWI as defined by eqs. 3 and 4, SAP, or CAP depending on what values are specified for Reset antecedent month \& day, Seasonal Antecedent Threshōld, AWI Threshold, Ant water Index Field Cap, AWI_drainage_Constant, and Hourly_Evap Consts

- RA precipitation threshold exceedance index, (eq. 8) $D_{R A}$

- ID threshold exceedance index, (eq. 6) $E_{I D}$

- Running-average-intensity exceedance index, (eq. 7) $E_{I D, f}$

- Base-10 logarithm of storm-average intensity, $\log _{10}\left(I_{o b s}\right)$, running-average intensity, and $\log _{10}\left(I_{o b s, f}\right)$
- The two-digit station number (first entry on each line under heading ListofstationNumbers Localities_InputFiles) may appear either as a column of data or in the output file name (indicated by $S S$ in file name). Also, the station number and locality name appear in one of the heading lines of the timeseries output files.

The user may choose between three output options for current conditions (table 1, line 37, P lot Format; table 2). If gnp 1 is chosen, a single data file, ThCurr.txt (table 3) will be provided containing the latest values for all the stations. If gnp2 is chosen, latest conditions will be written to a separate output file for each station (ThStaSS.txt, where $S S$ is the station number, table 3). Options gnp1 and gnp2 work for plotting with Gnuplot (http://www.gnuplot.info/), Python's matplot l ib (http://matplotlib.org/index.html), or other plotting routines and libraries that can reject lines of text preceded by a hashmark (\#). Options gnp1 and gnp2 are useful for continuous operating modes as either can be used to plot current conditions in real time. If dgrs is entered, a single file, ThCTpairs.txt, for all stations will be written in a format that can be used by interactive graphing or spreadsheet software. With this option, the heading lines do not have hash marks, and each line of output has a leading tab.

Current Alert Levels by Station and Threshold

\begin{tabular}{|c|c|c|c|c|c|}
\hline $\begin{array}{l}\text { Rain } \\
\text { gage }\end{array}$ & Vicinity & $\begin{array}{l}\text { Time and } \\
\text { date }\end{array}$ & $\begin{array}{c}\text { Recent- } \\
\text { antecedent }\end{array}$ & $\begin{array}{l}\text { Intensity- } \\
\text { duration }\end{array}$ & $\begin{array}{c}\text { 6-h running average } \\
\text { intensity }\end{array}$ \\
\hline 01 & $\begin{array}{l}\text { Seattle, Boeing } \\
\text { Field }\end{array}$ & $\begin{array}{c}10: 59 \\
16 \text { Feb } \\
2017\end{array}$ & Outlook & Watch & Outlook \\
\hline 02 & $\begin{array}{l}\text { Everett, Paine } \\
\text { Field }\end{array}$ & $\begin{array}{c}10: 59 \\
16 \text { Feb } \\
2017\end{array}$ & Null & Null & Null \\
\hline 03 & $\begin{array}{c}\text { Seattle-Tacoma } \\
\text { Airport }\end{array}$ & $\begin{array}{c}10: 59 \\
16 \mathrm{Feb} \\
2017\end{array}$ & Outlook & Watch & Outlook \\
\hline 04 & $\begin{array}{c}\text { Tacoma Narrow } \\
\text { Airport }\end{array}$ & $\begin{array}{c}10: 59 \\
16 \mathrm{Feb} \\
2017 \\
\end{array}$ & Outlook & Watch & Outlook \\
\hline \multicolumn{6}{|c|}{ EXPLANATION } \\
\hline & Null & \multicolumn{4}{|c|}{ Landslides very unlikely } \\
\hline & Outlook & \multicolumn{4}{|c|}{ Landslides might occur with additional rainfall } \\
\hline & Watch & \multicolumn{4}{|c|}{ Landslides likely with additional rainfall } \\
\hline & Warning & \multicolumn{4}{|c|}{ Landslides very likely } \\
\hline
\end{tabular}

Figure 3. Example of THRESH output file ThAlert.htm (table 3). Alert levels for the different thresholds are color-coded gray (null), yellow (outlook), orange (watch), or red (warning, not shown). Alert levels determined according to the scheme outlined in Baum and Godt (2010) for (1) the cumulative recent-antecedent (RA) threshold, (2) the intensityduration (ID) threshold and antecedent water index (AWI, not shown), and (3) the runningaverage intensity. h, hours. 
Current Conditions by Station

\begin{tabular}{|c|c|c|c|c|c|c|}
\hline $\begin{array}{l}\text { Rain } \\
\text { gage }\end{array}$ & $\begin{array}{l}\text { Vicinity of } \\
\text { rain gage }\end{array}$ & $\begin{array}{l}360-h \\
\text { antecedent total } \\
\text { (in) }\end{array}$ & $\begin{array}{c}\text { 72-h recent } \\
\text { total } \\
\text { (in) }\end{array}$ & $\begin{array}{c}\text { Average } \\
\text { intensity } \\
\quad(\text { in } / \mathbf{h})\end{array}$ & $\begin{array}{l}\text { Duration } \\
\text { of } \\
\text { current } \\
\text { storm } \\
\text { (h) }\end{array}$ & $\begin{array}{c}\text { Time } \\
\text { and date }\end{array}$ \\
\hline 01 & $\begin{array}{l}\text { Seattle, Boeing } \\
\text { Field }\end{array}$ & 2.52 & 3.28 & 0.065 & 45.0 & $\begin{array}{c}05: 59 \\
09 \text { Dec } \\
2015\end{array}$ \\
\hline 02 & $\begin{array}{l}\text { Everett, Paine } \\
\text { Field }\end{array}$ & 2.09 & 2.51 & 0.060 & 26.0 & $\begin{array}{c}05: 59 \\
09 \mathrm{Dec} \\
2015\end{array}$ \\
\hline 03 & $\begin{array}{c}\text { Seattle-Tacoma } \\
\text { Airport }\end{array}$ & 2.49 & 3.73 & 0.075 & 48.0 & $\begin{array}{c}05: 59 \\
09 \mathrm{Dec} \\
2015\end{array}$ \\
\hline 04 & $\begin{array}{c}\text { Tacoma Narrows } \\
\text { Airport }\end{array}$ & 1.76 & 3.65 & 0.000 & 0.0 & $\begin{array}{c}05: 59 \\
09 \mathrm{Dec} \\
2015\end{array}$ \\
\hline
\end{tabular}

Figure 4. Example of THRESH output file ThCurrTabl.htm (table 3). Note that the file ThCurrTabl.txt contains the same information in plain-text format. The lime cell has storm rainfall intensity $(0.060$ inches per hour [in/h]) in the range $0.6-0.8$ of the intensity-duration (ID) threshold at $26 \mathrm{~h}\left(0.73=0.060 /\left(3.257\left(26^{-1.13}\right)\right)\right.$; similarly, the magenta cells have rainfall intensity in the range that is $>1.4$ times greater than the ID threshold. Cells are color coded based on the values in the file Colors.txt (table 4). h, hours; in, inches.

\section{Choosing Colors for the ThCurrTabl.htm File}

The file Colors.txt controls the colors in the optional HTML table ThCurrTabl.htm. When the program, THRESH, is running in continuous mode, the HTML table gives the user a quick visual and numerical guide to current precipitation conditions relative to the ID threshold. Modification of the file Colors.txt enables the user to select display colors and ranges of intensity to highlight rainfall intensities of potential concern. The file Colors.txt, should always be placed in the same directory as the initialization file thresh in.txt. The Colors.txt file currently contains nine color tags (hexadecimal values) and eight intervals of intensity (the color will change as the intensity passes into each interval). The current setup of Colors.txt and a description of its contents can be found in table 4. The file contains one entry per line (left column, "Contents"). Line 1 indicates the number of intervals (8), lines 2-10 indicate the hexadecimal number corresponding to a particular color, and lines 11-18 indicate the boundaries between the color intervals, as explained in the column on the right side of table 4 . THRESH assigns colors using the ratio of intensity to the ID threshold (eq. 6, $E_{I D}$ ). In most cases, three or four intervals may be adequate, and the user can edit the file to delete colors that are not needed and to specify the intervals of interest.
Table 4. Listing and explanation of input file Colors.txt.

[See equation 6 for more details. $E_{I D}$, the index for exceedance of the ID threshold]

\begin{tabular}{lll}
\hline \multicolumn{1}{c}{ Contents } & \multicolumn{1}{c}{ Color name } & \multicolumn{1}{c}{ Interval of appearance } \\
\hline${ }^{1} 8$ & White & $E_{I D} \leq 0.0$ \\
$\mathrm{ffffff}^{2}$ & LightGrey & $0.0<E_{I D} \leq 0.2$ \\
$\mathrm{~d} 3 \mathrm{~d} 3 \mathrm{~d} 3$ & Lavender & $0.2<E_{I D} \leq 0.4$ \\
e6e6fa & Aqua & $0.4<E_{I D} \leq 0.6$ \\
$00 \mathrm{ffff}$ & Lime & $0.6<E_{I D} \leq 0.8$ \\
$00 \mathrm{ff00}$ & Yellow & $0.8<E_{I D} \leq 1.0$ \\
ffff00 & Orange & $1.0<E_{I D} \leq 1.2$ \\
ffa500 & Red & $1.2<E_{I D} \leq 1.4$ \\
ff0000 & Magenta & $1.4<E_{I D}$ \\
ff00ff & \\
0.0 & \\
0.2 & \\
0.4 & \\
0.6 & \\
0.8 & \\
1.0 & \\
1.2 & \\
1.4 & \\
\hline${ }^{1}$ This integer indicates the number of intervals. \\
${ }^{2}$ Color codes are hexadecimal values used to specify colors in hypertext \\
markup language (HTML). Color names are HTML standard color names \\
recognized by all web browsers. See http://www.w3schools.com/colors/ \\
colors_names.asp for additional colors.
\end{tabular}




\section{Utility Programs}

The following sections briefly describe the two utility programs, NWSFMT and TSTHRESH, various Python scripts to support plotting and data collection, and shell scripts and batch files to support automated operation of the programs in this distribution.

\section{NWSFMT}

The utility program NWSFMT is designed to read data files in certain formats and reformat data into a form readable by THRESH (fig. 1). NWSFMT operates from the command line and depends on several input files: $n w s f m t$ in.txt, date.txt, and text files of raw input data. An example listing of the initialization file, $n w s f m t$ in.txt, is shown in table 5. Inputs on lines 1-7 and 9 are a subset of inputs in tables 1 and 2. Inputs must be listed in the order shown in table 5 . NWSFMT needs the number of stations (table 5, line 1); the maximum number of lines of input data per station to expect (line 2); a listing of input data files, each on a separate line (lines 3-7); a flag indicating whether to append output data onto an existing file or overwrite the contents of the output file (line 8); and the frequency of the input data in (equally spaced) readings per hour (line 9). The example in table 5 assumes that data from four stations are to be processed. The number of lines of input data files listed below line 3 should agree with the specification on line 1. Inputs shown on lines 8 and 9 in table 5 always follow the list of input files and are the last two lines in the file regardless of the number of input files listed ahead of them.

The file date.txt includes the date of the latest data in the input files listed in nwsfmt_in.txt. The date is given in the format WWW MON DD HH:MM:SS YYYY, where WWW is the three-character weekday abbreviation, MON is the three-character month abbreviation, DD is the two-digit date, HH is the two-digit hour (24-h clock, Coordinated Universal Time [UTC]), MM is the two-digit minutes, SS is the twodigit seconds, and YYYY is the four-digit year, for example "Mon Nov 21 16:30:00 2016." The file date.txt has been used to ensure that the data were identified with the correct month and year in continuous mode when precipitation data were extracted from weather web pages listing recent readings with only date and time (no year or month) in HTML format.

The standard precipitation input format for NWSFMT is a tab-delimited text file containing date, time, and precipitation. The inputs are listed in four columns as follows: $\mathrm{DD}<\mathrm{tab}>\mathrm{HH}<\mathrm{tab}>\mathrm{MM}<\mathrm{tab}>\mathrm{P}$.PP, where $\mathrm{DD}, \mathrm{HH}$, and $\mathrm{MM}$ are as described in the previous paragraph, " $<\mathrm{tab}>$ " represents the tab character, and P.PP is the precipitation. For example, "19 $12 \quad 53 \quad 0.02$ " represents a line from such an input file, and indicates 0.02 in. of precipitation was recorded in the hour preceding 12:53 local time on the 19th day of the current month. Month and year are obtained from the file date.txt, as explained previously.
Table 5. Listing of an example initialization file named nwsfmt_in.txt for the program NWSFMT.

[For the line numbers, this is a plain-text representation of the initialization file without any formatting conventions; only the file name at the top of column 2 is formatted in italics]

\begin{tabular}{cl}
\hline $\begin{array}{c}\text { Line } \\
\text { number }\end{array}$ & \multicolumn{1}{c}{ nwsfmt_in.txt } \\
\hline 1 & Number_Of_Stations,4 \\
2 & Number_Of_Data_Lines,500 \\
3 & List_Of_Station_Numbers_Localities_InputFiles \\
4 & 01,'Seattle,Boeing Field','KBFI.txt' \\
5 & 02,'Everett,Paine Field','KPAE.txt' \\
6 & 03,'Seattle-Tacoma Airport','KSEA.txt' \\
7 & 04,'Tacoma Narrows Airport','KTIW.txt' \\
8 & AppendData?, .TRUE. \\
9 & ReadingsPerHour,1 \\
\hline
\end{tabular}

Output files are stored in the same location as input files and use modified names of corresponding input files. The program NWSFMT appends, $t$ onto the end of the file name, before the .txt suffix. Thus, for example, KBFI t.txt is the output file corresponding to the input file KBFI.txt.

\section{TSTHRESH}

The program TSTHRESH is used for computing statistics used by the receiver-operating characteristics (ROC) method for testing and optimizing precipitation thresholds (Staley and others, 2013). The program uses sorted lists of some measure of precipitation, such as cumulative precipitation for a specific time interval or precipitation intensity, to compute the ROC statistics for that measure. Each input file contains a single column of values that have been extracted from the long-term output file ThArchiveSS.txt and sorted from smallest to largest. For each precipitation measure to be tested, two sorted lists are needed: one list containing values of the measure only at times when landslides occurred and one for the entire period of record (table 6). All duplicates must be retained during sorting (for example, if the 72-h recent precipitation total reached the same value on 12 different occasions during the period of record, each should be included in the input file in file 72hour_sort.txt listed on line 2 of table 6). The shorter column of values for landslide occurrence has been reduced by eliminating all values that do not match times of landslide activity before sorting. The initialization file for TSTHRESH, tsth in.txt, contains a list of input files with an appropriate identifier (such as the associated time increment or duration for the cumulative precipitation amount or intensity) for each pair of input files (table 6). The identifier, listed on line 1 of table 6 , is used in naming the output file. The sorted input file containing values for the entire record is listed on line 2, and the input file that contains data only for times of landslide activity is listed on line 3 . The pattern may be repeated for as many pairs of input files as desired (lines 4-6). Inputs must be listed in the 
Table 6. Listing of an example initialization file named tsth_in.txt for the program TSTHRESH.

[This is a plain-text representation of the initialization file without any formatting conventions; only the file name at the top of column 2 is formatted in italics]

\begin{tabular}{cll}
$\begin{array}{c}\text { Line } \\
\text { number }\end{array}$ & \multicolumn{1}{c}{ tsth_in.txt } & \multicolumn{1}{c}{ Description } \\
\hline 1 & 72 & Time increment or other identifier used to name output file (up to 24 characters). \\
2 & $. / 3-15 / 72$ hour_sort.txt & Path to input file containing sorted list for entire record (up to 255 characters). \\
3 & $. / 3-15 / 72$ hour_sort_sl.txt & Path to input file containing sorted list for times of landslide activity only. \\
4 & awi & Same as line 1. \\
5 & $. / 3-15 /$ awi_sort.txt & Same as line 2. \\
6 & $. / 3-15 /$ awi_sort_sl.txt & Same as line 3. \\
\hline
\end{tabular}

order indicated in table 6. TSTHRESH runs from the command line and sends output for each pair of input files to a separate file named TS_[identifier].txt, where [identifier] corresponds to the numeric or text identifier (lines 1 and 4, table 6). An example shell script, roc.sh (table 7), and supporting input data folder LandslideThresholds/data/test/ for demonstrating the use of TSTHRESH are available as part of this software distribution. A companion report by Scheevel and others (2017) demonstrates how output results from TSTHRESH are used to calibrate and validate precipitation thresholds.

\section{Shell Scripts and Corresponding Batch Files}

The software distribution includes a small collection of shell scripts and equivalent batch files that can be used with THRESH to automate tracking of precipitation thresholds and simplify analysis of long-term precipitation data for testing or calibrating thresholds. The shell scripts, counterpart batch files, and their purpose are listed in table 7. These scripts will require minor editing before using them in the examples that accompany this user manual. They will typically require more extensive editing before using them for other projects and can be used as templates for setting up workflows for new stations.

\section{Python Scripts}

This distribution includes Python scripts written for Python 2.7 to demonstrate processing and plotting of precipitation data for tracking precipitation thresholds. We have also included a number of related scripts for processing and plotting instrumental data that might be used to supplement precipitation thresholds for characterizing time-varying potential for precipitation-induced landslides. Table 8 lists the Python scripts and describes their intended function. These scripts have a number of dependencies on Python packages

Table 7. Listing of shell scripts and corresponding Microsoft ${ }^{\circledR}$ Windows ${ }^{\circledR}$ batch files and intended purpose.

[These scripts are templates that would require minor to moderate revisions before using them for other stations. Python scripts mentioned in this table are described in table 8. Directories and file names, including Python scripts, shell scripts, and batch files, are typed in italic. Programs are in all uppercase letters]

\begin{tabular}{|c|c|c|}
\hline $\begin{array}{l}\text { Shell } \\
\text { script }\end{array}$ & $\begin{array}{l}\text { Batch } \\
\text { file }\end{array}$ & Purpose and description \\
\hline data.sh & data.bat & $\begin{array}{l}\text { Manage and plot instrumental data-copies latest instrumental measurements from source into local folder } \\
\text { (data/RALHS/), extracts precipitation measurements into separate files, invokes Python scripts to process } \\
\text { and plot data, copies plots to web server, and splits and archives precipitation files annually. }\end{array}$ \\
\hline rain.sh & rain.bat & $\begin{array}{l}\text { Manage and plot data from public weather stations-runs scripts NWS.py and Forecast.py, copies plots to } \\
\text { web server, and splits and archives precipitation files annually. }\end{array}$ \\
\hline startData.sh & startData.bat & $\begin{array}{l}\text { Construct initial set of input files for plotting and threshold tracking-uses a subset of commands in data.sh } \\
\text { to copy entire record of instrumental measurements from source into local folder (data/RALHS/), and } \\
\text { extract precipitation measurements into files readable by the program THRESH. }\end{array}$ \\
\hline
\end{tabular}


Table 8. Listing of Python scripts with this distribution (see folder src/pyth_scripts/ for processing and plotting data and intended purpose.

[These scripts are templates that would require minor to moderate revisions before using them for other stations. kPa, kilopascal; RA, cumulative recentantecedent; ID, intensity-duration. Directories and file names, including Python scripts, shell scripts, and batch files, are typed in italic]

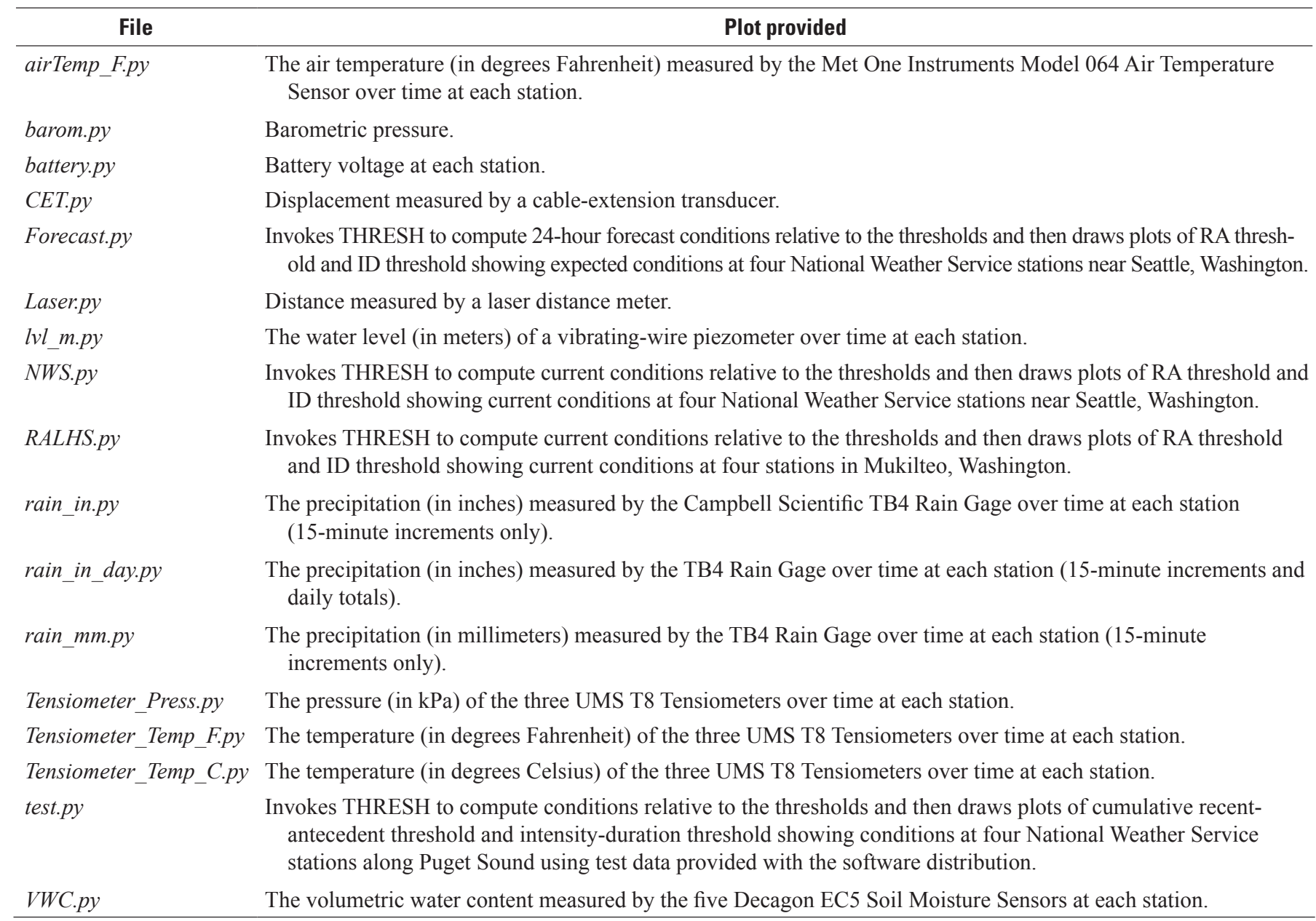

and libraries that can be satisfied either by installing all the necessary packages separately or by installing Anaconda, as noted previously. Although all are working scripts, most contain output text (labels), parameters, formulas, and reference to input files that are specific to particular stations in the examples. Thus the scripts should be considered templates, as they would require considerable editing before they could be used elsewhere. Additional description is available within the comment lines of these scripts, but a complete description of each Python script listed in table 8 is beyond the scope of this user manual. Figures 5-8 show examples of plots generated by the Python script NWS.py. 
Current conditions near Seattle, Washington,

with respect to recent-antecedent precipitation threshold for the occurrence of landslides

USGS PROVISIONAL DATA

SUBJECT TO REVISION

Data last updated: 28 Nov 2017, 11:59.

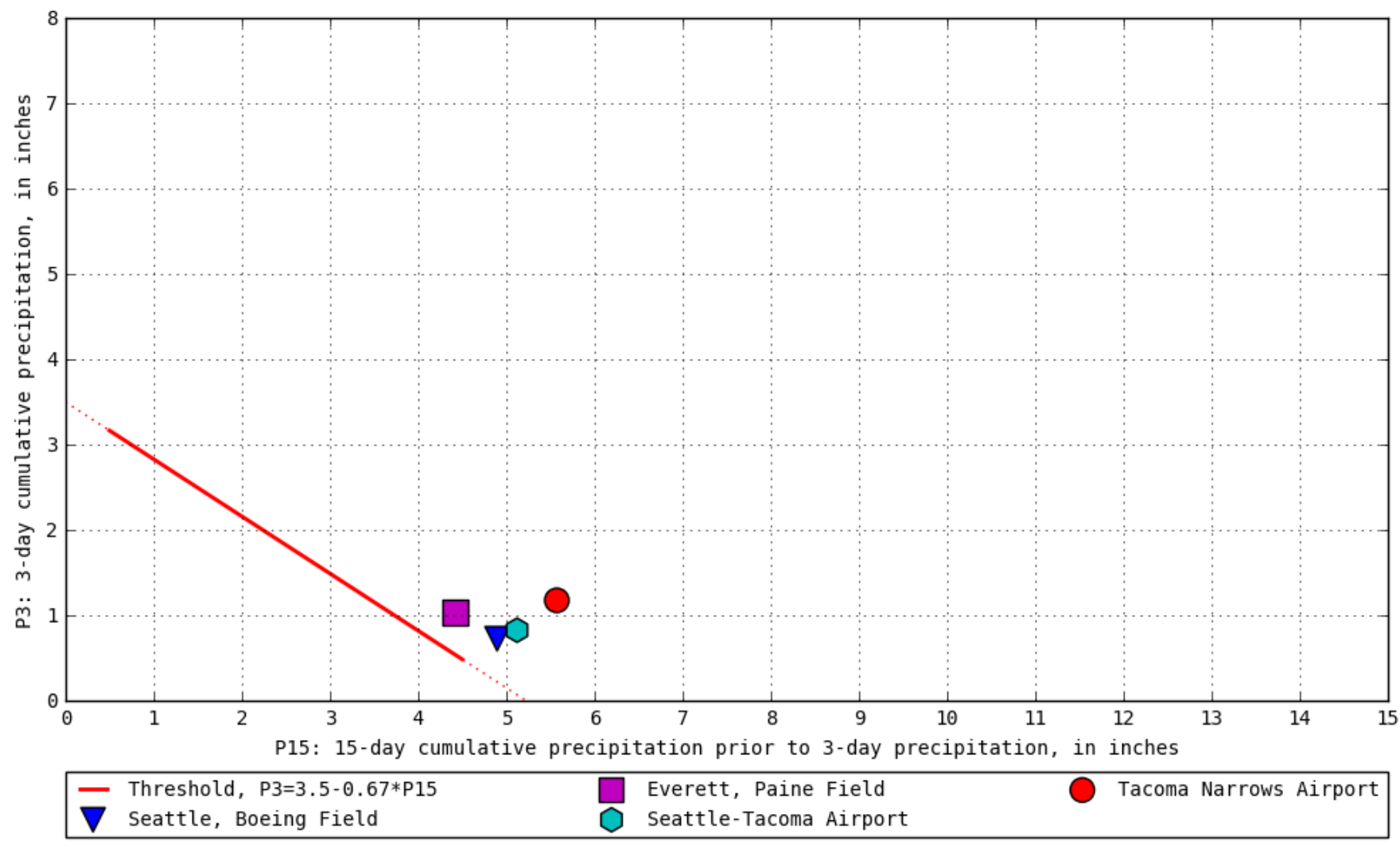

Figure 5. Example plot showing current conditions at four stations relative to the cumulative 3-day recent and 15-day antecedent precipitation threshold of Chleborad and others (2008). Recent precipitation corresponds to the vertical axis and antecedent precipitation to the horizontal axis. The axis labels describe the precipitation amounts that comprise the recent and antecedent precipitation. The plot was generated by the Python script NWS.py using files ThSta01.txt, ThSta02.txt, ThSta03.txt, and ThSta04.txt as input. 
360-hour precipitation history near Seattle, Washington,

with respect to recent-antecedent precipitation threshold for the occurrence of landslides USGS PROVISIONAL DATA

SUBJECT TO REVISION

Data last updated: 28 Nov 2017, 11:59.

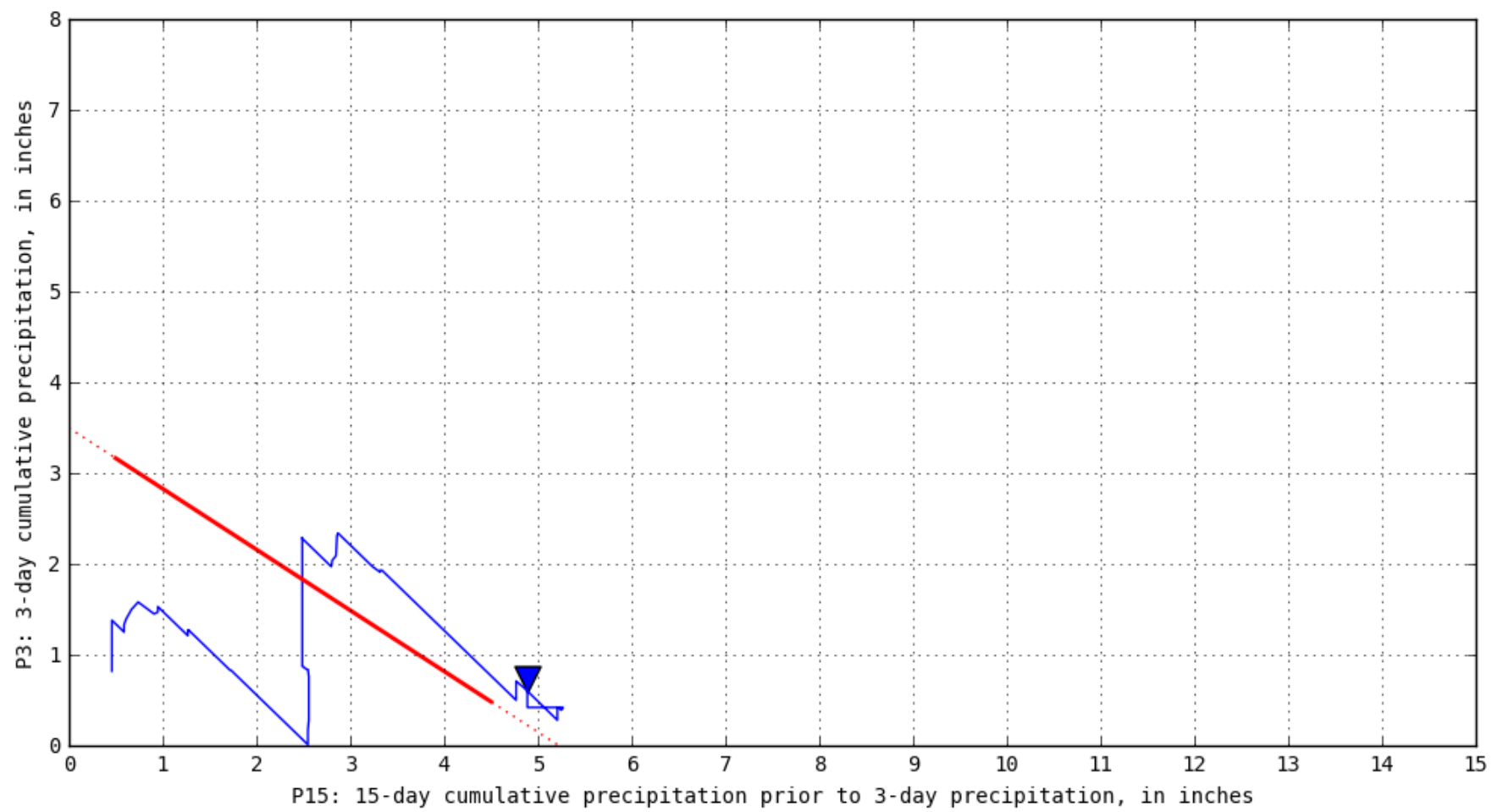

Figure 6. Example plot showing current conditions and 15-day history of conditions at Boeing Field relative to the cumulative 3-day recent and 15-day antecedent precipitation threshold (Chleborad and others, 2008). Recent precipitation corresponds to the vertical axis and antecedent precipitation to the horizontal axis. The axis labels describe the precipitation amounts that comprise the recent and antecedent precipitation. The plot was generated by the script NWS.py using the THRESH output files ThSta01.txt and ThTSplot360hour01.txt as input. 
Current conditions near Seattle, Washington,

with respect to precipitation intensity and duration threshold for the occurrence of landslides USGS PROVISIONAL DATA

SUBJECT TO REVISION

Data last updated: 28 Nov 2017, 11:59.

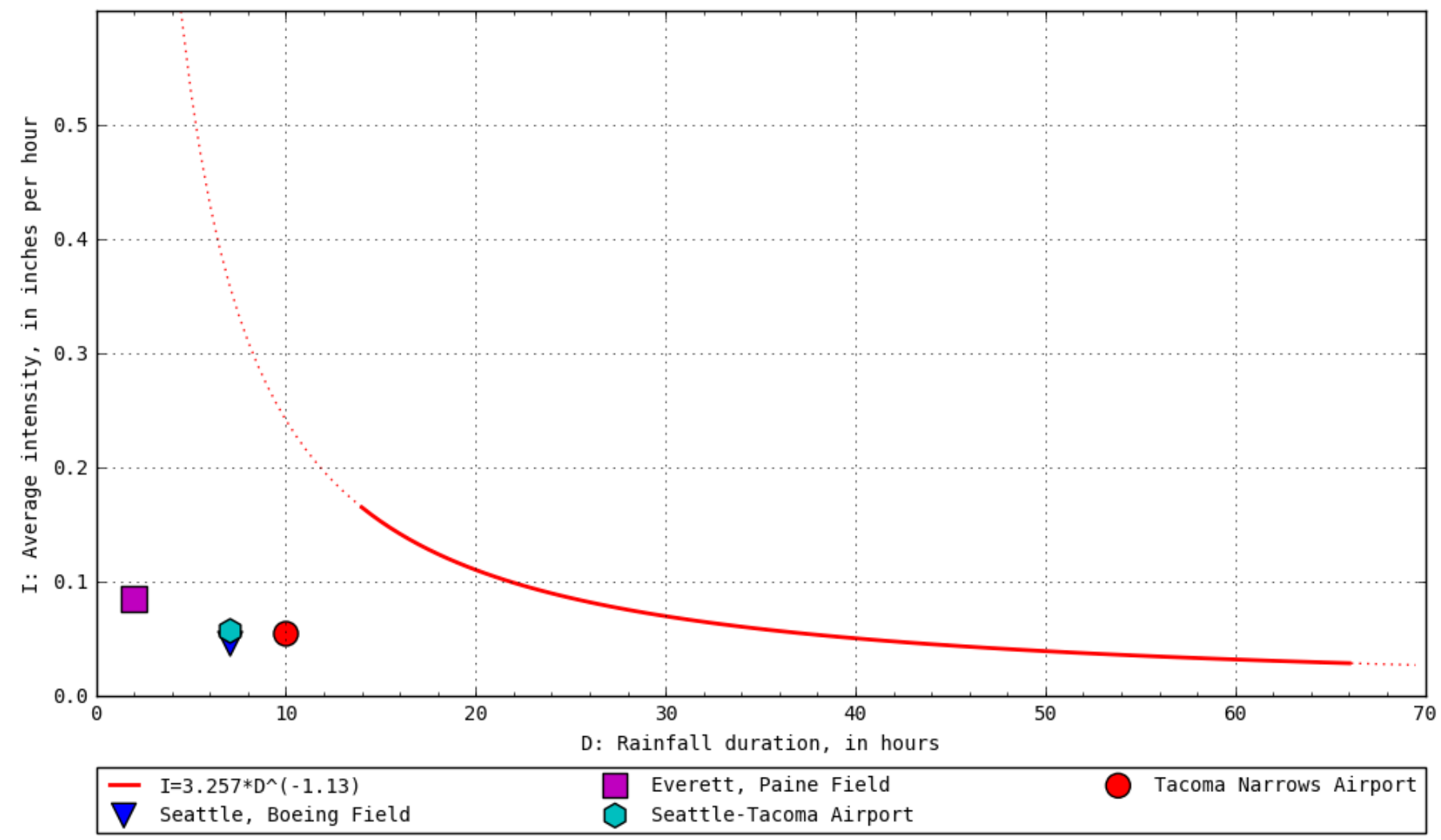

Figure 7. Example plot of storm average intensity (eq. 6, I obs), and duration (eq. 1, D), for four weather stations (where intensity is near zero for all stations). The red curve indicates the published intensity-duration (ID) threshold (eq. 1) for the area covered by the weather stations (Godt and others, 2006). The plot was generated by the Python script NWS.py using files ThSta01.txt, ThSta02.txt, ThSta03.txt, and ThSta04.txt as input. 
360-hour Precipitation History near Seattle, Washington,

with respect to the Antecedent water index for the occurrence of landslides

USGS PROVISIONAL DATA

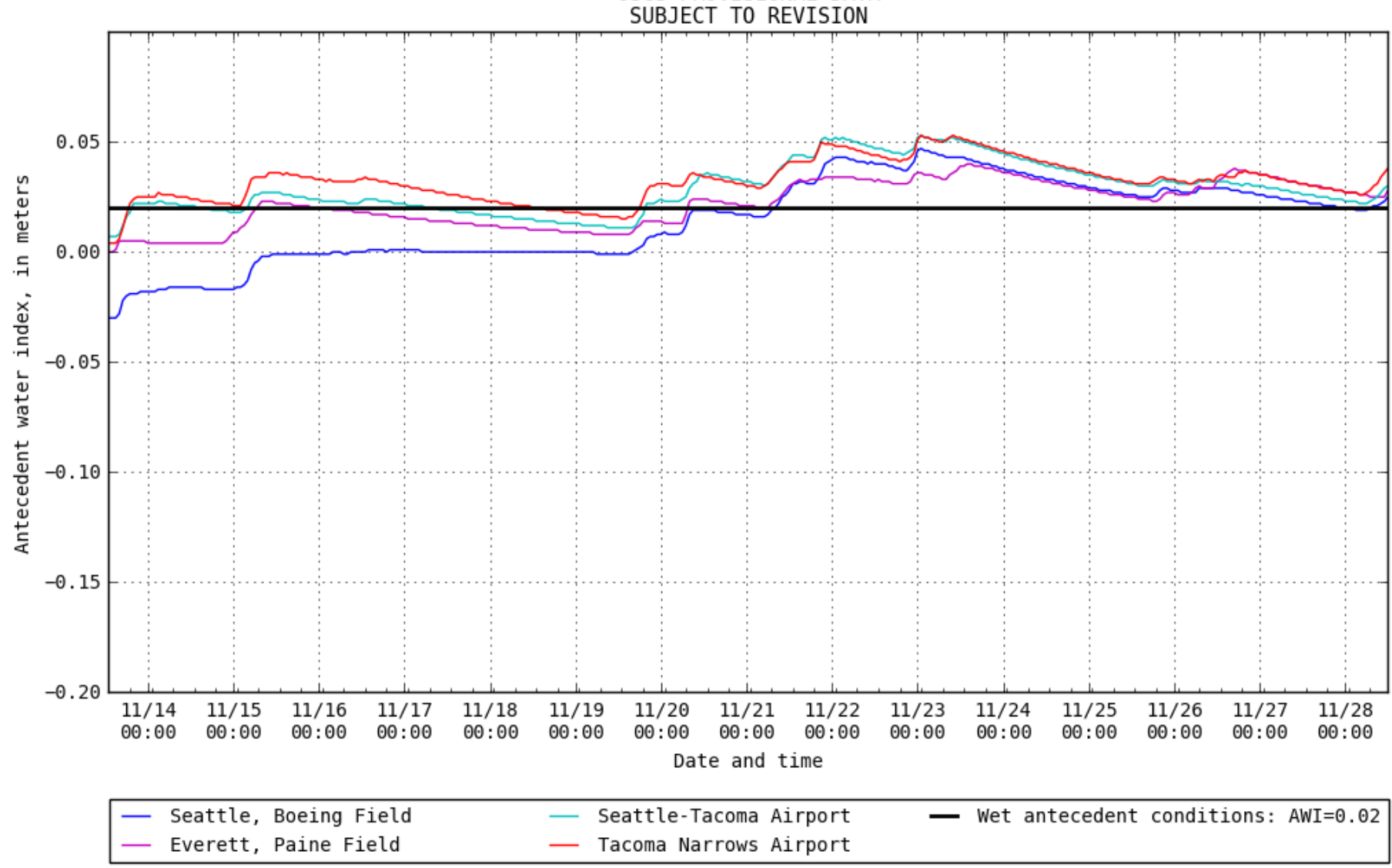

Figure 8. Example of plot showing a 15-day history of the antecedent water index (AWI) for each of four weather stations. The plot was generated by the Python script NWS.py using files ThTSplot360hour01.txt, ThTSplot360hour02.txt, ThTSplot360hour03.txt, and ThTSplot360hour04.txt as input. 


\section{Acknowledgments}

Caroline Scheevel and Dianne Brien (both USGS) provided constructive reviews of the manuscript and software. Work to improve the software and prepare documentation for public release resulted from our recent cooperation with Sound Transit to improve precipitation thresholds for the rail corridor near Mukilteo and Everett, Washington, and to incorporate rainfall forecasts into precipitation tracking to enhance early warning for landslides. Weylin Doyle and Martin Young (both of Sound Transit) provided input on the types of charts that would be useful for interpreting the thresholds.

\section{References Cited}

Baum, R.L., and Godt, J.W., 2010, Early warning of rainfallinduced shallow landslides and debris flows in the USA: Landslides, v. 7 no. 3, p. 259-272. [Also available at https://doi.org/10.1007/s10346-009-0177-0.]

Caine, Nel, 1980, The rainfall intensity-Duration control of shallow landslides and debris flows: Geografiska Annaler, v. 62A, nos. 1-2, p. 23-27. [Also available at http://www.jstor.org/stable/520449.]

Campbell, R.H., 1975, Soil slopes, debris flows, and rainstorms in the Santa Monica Mountains and vicinity, southern California: U.S. Geological Survey Professional Paper 851, 51 p. [Also available at https://pubs.er.usgs.gov/ publication/pp851.]

Chleborad, A.F., 2003, Preliminary evaluation of a precipitation threshold for anticipating the occurrence of landslides in the Seattle, Washington, area [ver. 1]: U.S. Geological Survey Open-File Report 03-463, accessed November 22, 2017, at https://pubs.usgs.gov/of/2003/ofr-03-463/.

Chleborad, A.F., Baum, R.L., and Godt, J.W., 2006, Rainfall thresholds for forecasting landslides in the Seattle, Washington, area-Exceedance and probability: U.S. Geological Survey Open-File Report 2006-1064, 31 p., accessed November 22, 2017, at https://pubs.usgs.gov/of/2006/1064/.

Chleborad, A.F., Baum, R.L., Godt, J.W., and Powers, P.S., 2008, A prototype system for forecasting landslides in the Seattle, Washington, area: Geological Society of America Reviews in Engineering Geology, v. 20, p. 103-120. [Also available at https://doi.org/10.1130/2008.4020(06).]

Godt, J.W., Baum, R.L., and Chleborad, A.F., 2006, Rainfall characteristics for shallow landsliding in Seattle, Washington, USA: Earth Surface Processes and Landforms, v. 31, no. 1, p. 97-110. [Also available at https://doi.org/10.1002/ esp.1237.]

Guzzetti, Fausto; Peruccacci, Silvia; Rossi, Mauro; and Stark, C.P., 2008, The rainfall intensity-Duration control of shallow landslides and debris flows-An update: Landslides, v. 5, no. 1, p. 3-17. [Also available at https://doi.org/10.1007/s10346-007-0112-1.]

Keefer, D.K., Wilson, R.C., Mark, R.K., Brabb, E.E., Brown, W.M., III, Ellen, S.D., Harp, E.L., Wieczorek, G.F., Alger, C.S., and Zatkin, R.S., 1987, Real-time landslide warning during heavy rainfall: Science, v. 238, no. 4829, p. 921-925. [Also available at http://www.jstor.org/stable/1700926.]

Mirus, B.B., Smith, J.B., Stark, Benjamin, Lewis, York, Michel, Abigail, and Baum, R.L., 2016, Assessing landslide potential on coastal bluffs near Mukilteo, WashingtonGeologic site characterization for hydrologic monitoring: U.S. Geological Survey Open-File Report 2016-1082, 28 p., accessed November 22, 2017, at http://dx.doi.org/10.3133/ofr20161082.

Scheevel, C.R., Baum, R.L., Mirus, B.B., and Smith, J.B., 2017, Precipitation thresholds for landslide occurrence near Seattle, Mukilteo, and Everett, Washington: U.S. Geological Survey Open-File Report 2017-1039, 51 p., accessed November 22, 2017, at https://oi.org/10.3133/ ofr20171039.

Smith, J.B., Baum, R.L., Mirus, B.B., Michel, A., and Stark, B., 2017a, Results of hydrologic monitoring on landslideprone coastal bluffs near Mukilteo, Washington: U.S. Geological Survey Open-File Report 2017-1095, 47 p., accessed November 22, 2017, at http://dx.doi.org/10.3133/ ofr20171095.

Smith, J.B., Baum, R.L., Mirus, B.B., Michel, A., and Stark, B., 2017b, Results of hydrologic monitoring on landslide-prone coastal bluffs near Mukilteo, Washington, U.S. Geological Survey data release, accessed November 22, 2017, at https://doi.org/10.5066/F7NZ85WX.

Staley, D.M., Kean, J.W., Cannon, S.H., Schmidt, K.M., and Laber, J.L., 2013, Objective definition of rainfall intensity-Duration thresholds for the initiation of postfire debris flows in southern California: Landslides, v. 10, no. 5, p. 547-562, accessed August 7, 2017, at https://doi.org/10.1007/s10346-012-0341-9.

Wieczorek, G.F., and Sarmiento, John, 1988, Rainfall, piezometric levels, and debris flows near La Honda, California, in storms between 1975 and 1983, in Ellen, S.D., and Wieczorek, G.F., eds., Landslides, floods, and marine effects of the storm of January 3-5, 1982, in San Francisco Bay region, California: U.S. Geological Survey Professional Paper 1434, p. 43-62. [Also available at https://pubs.er.usgs.gov/publication/pp1434.]

Wilson, R.C., and Wieczorek, G.F., 1995, Rainfall thresholds for the initiation of debris flows at La Honda, California: Environmental and Engineering Geoscience, v. 1, no. 1, p. 11-27. [Also available at https://doi.org/10.2113/ gseegeosci.I.1.11.] 
Appendixes 


\section{Appendix 1. Seattle, Washington, Example}

We have provided a sample set of input files to demonstrate the operation and options provided by THRESH. These files can be found in the test folder in the data folder (LandslideThresholds/data/test/) and contain hourly precipitation data covering a period of several months for four rain gage stations in the Seattle, Washington, area. This example provides information on the content of the initialization file (thresh_in.txt) for these sample datasets. All the input parameters in the sample initialization file are specific to the sample data so that no editing of the initialization file is required to run the example. The various options for output files, intensity-duration (ID) thresholds, and statistics will be explained as well. Study of the output files will help the user become familiar with the types of results that can be expected.

\section{Preparing the THRESH Initialization File for an Analysis}

To view the THRESH initialization file, open the file thresh_in.txt in the data/test/ folder. The contents should closely resemble table 1 . Table 2 provides an explanation of each variable, and table 3 is a list of potential output files produced by the program. The options chosen by the user will control the number of and format for output files (table 3), which will be outlined in the following paragraphs.

\section{Format of Input Data}

The first four lines of the initialization file contain information that enables the program to read the input files. Since the sample dataset provided contains precipitation from four stations, the number of stations is specified as 4 in line 1. Each of the input files contains about 12,600 lines of data, so the number of data lines (line 2) can be set to any number equal to or greater than the maximum number of lines per station. Here we have set the value to 40000 to allow for larger input files. Readings were taken every hour, so the readings per hour (line 3 ) are set to 1 . Lastly, line 4 provides an option for the unit of precipitation measurements, in inches (in.) for this example.

\section{Storm Information}

The user may choose information to track storms based on the location of the rain gages for lines 5-9. The example file is based on parameters for the Seattle area (Chleborad and others, 2008): line 5 (Recent_Hours) is 72 , and line 6 (Antecedent_Hours) is 360. If the user wishes to specify the number of hours used in computing a runningaverage (mean) intensity, a positive, nonzero value may be put in for Intensity_Hours (line 7). The default value is 0 (zero) and results in computing the storm-average intensity commonly used in ID thresholds. The line labeled Hours_Between_Storms (line 8) is the number of hours of no rainfall needed to compute the storm-average intensity. This is a climate-dependent parameter. Godt and others (2006) determined that for the Seattle, Washington, area, periods of rainfall separated by at least 3 hours (h) should be treated as separate storms when applying the ID threshold. Hence, 3 is entered on line 8. During a rainfall event, the computed duration increases steadily while rain continues, pauses during short periods of no rainfall, resumes when rainfall resumes if time between storms has not been exceeded, and stops after the time between storms is exceeded, as explained previously (eqs. 1 and 2). Elapsed time between beginning and end of rainfall, including short gaps ( $3 \mathrm{~h}$ or less in this example) of no rainfall, is the storm duration. Lastly, a second, optional running-average intensity (eq. 7) can be used (line 9). For this illustration, a 6-h intensity will be computed (line 9).

\section{Plotting Information}

Line 10, gap length, is the maximum length in number of lines of new input data for the gap between the latest data and the end of previous data. We have used 9,000 in this case; however, a smaller value can be specified when using THRESH for continuous operations. The value 9000 that would allow for slightly more than a 1-year gap in hourly data is greater than needed in this example but raises the point that a long-term dataset with a significant gap can be analyzed by separating the input data into two separate files with combined output. Lines 11-12 set the length of time covered by output files for plotting time-series of recent conditions. The values of the short and long plot windows on lines 11 and 12 are 36 and $360 \mathrm{~h}$ ( 1.5 and 15 days) respectively for this example. These values result in THRESH saving output for the last 36 and $360 \mathrm{~h}$ to files named ThTSplot36hourSS.txt and ThTSplot360hourSS.txt, where SS is the two-digit station number. For this example, we obtain a total of eight output files (two for each station), which may be used as input by plotting routines. For example, the script NWS.py creates time-series plots from the 360 -h files.

\section{Recent-Antecedent Precipitation Threshold}

The slope and intercept used for defining the cumulative recent-antecedent (RA) precipitation values (lines 13-14) were calculated by Chleborad and others (2008) to reflect slope stability of the Seattle area. Slope and intercept as well as number of days for summing the recent and antecedent precipitation amounts may be different in other areas where this kind of precipitation threshold can be applied. 


\section{Definition of Intensity-Duration Thresholds}

Lines 15-24 provide the user with three options for defining the ID threshold, as mentioned previously. The threshold unit (line 24) is inches for this example regardless of the method used to define the threshold. It is permissible to define the threshold in millimeters $(\mathrm{mm})$ and use precipitation measured in inches as input.

- Case 1.- The ID threshold is defined by the power law (eq. 1). To use a power-law threshold, we entered . TRUE. on line 15 and . FALSE. on lines 19 and 22. Lines 16 and 17 contain the coefficient and exponent used in defining this power function, and the values shown are specifically for the Seattle area. The lower $\left(D_{\min }\right)$ and upper $\left(D_{\max }\right)$ limits (line 18) of the threshold are set to values of 0 and $60 \mathrm{~h}$ for this example.

- Case 2.-The ID threshold follows a smooth curve that is poorly represented by a power law, but a polynomial can be fit to the threshold. In this case, we would enter .FALSE on lines 15 and 22 and. TRUE. on line 19, so that the ID threshold will be calculated using a fifthdegree polynomial. Lines 20-21 contain the polynomial coefficients (and units) and duration interval. The user would list $I_{0}$ followed by $c_{1}, \ldots, c_{5}$ as defined in eq. 2 on line 20 and $D_{\min }$ followed by $D_{\max }$ on line 21 .

- Case 3.-The ID threshold is only defined at discrete points. To use this kind of threshold, the user would enter . FALSE. on lines 15 and 19 and . TRUE. on line 22, so that the ID threshold will be defined by linearly interpolating intervals, which will require an input file named interpolatingPoints.txt. This software distribution includes an example of interpolatingPoints.txt in the folder data/NWS as shown in table 1-1. Since the example file contains six interpolating points, the line labeled Number_Of_Interpolating_Intervals (line 23 of thresh_in.txt) would be set to 5 for this example. Note that the file interpolatingPoints.txt must be placed in the same folder as the file thresh_in.txt. In addition, the user can edit the file interpolatingPoints.txt to have any desired number of intervals. The file contains duration (left column) and intensity (right column) pairs, one per line in a plain text file. The file has no heading and the columns can be tab, comma, or space delimited. In this case, $D_{\min }$ and $D_{\max }$ are defined by the first (10) and last (53) interpolating points, so no entry exists for them in the initialization file.
Table 1-1. Example of input file interpolatingPoints.txt.

\begin{tabular}{cc}
\hline $\begin{array}{c}\text { Duration } \\
\text { (hours) }\end{array}$ & $\begin{array}{c}\text { Intensity } \\
\text { (inches per hour) }\end{array}$ \\
\hline 10 & 0.241 \\
20 & 0.110 \\
30 & 0.069 \\
40 & 0.050 \\
50 & 0.039 \\
53 & 0.037 \\
\hline
\end{tabular}

\section{Antecedent Precipitation Information}

The next seven lines (25-31) of the file thresh_in.txt contain information on the antecedent water index (AWI), seasonal antecedent threshold (SAT), and evaporation constants. These values, which include the running-averageintensity threshold, AWI threshold, field capacity of soil used in computing the AWI, drainage constant used in computing the AWI, and the hourly evaporation constants for each month, are examples specific to the Seattle area and the dataset provided for this example. However, they (as well as other parameters in thresh_in.txt) can be changed for datasets from a different locality after this example is completed.

The program THRESH will check parameters for the SAT and AWI for completeness to determine which will be computed. The SAT will be computed if both are complete; cumulative annual precipitation will be computed if parameters for neither SAT or AWI are complete. For the example shown here, all three numeric values for the SAT (lines 25-26) are 0 (zero), but a complete set of values is listed for the AWI (lines 28-31), so the AWI will be computed. Note also that dimensions (units) of the AWI (either in feet or meters), the drainage constant (line 30 ), and the AWI threshold (line 28) are controlled by the field capacity (line 29). The evaporation constants for this example (line 31 ) were computed from average monthly evapotranspiration potential values using the formula

$$
E T_{h}=\frac{c_{u} E T_{m}}{24 d_{m}}
$$

where

$$
\begin{array}{cl}
E T_{h} & \text { is the hourly value (in hundredths of an inch } \\
& \text { in this example); } \\
E T_{m} & \text { is the monthly average (inches in this } \\
& \text { example); } \\
d_{m} & \text { is the number of days in the month; } \\
c_{u} & \text { is the factor to convert the units of } E T_{m} \text { into } \\
& \text { the units of } E T_{h}(100 \text { in this example }) .
\end{array}
$$

To use the SAT, a user would enter positive, nonzero values for the parameters on lines 25-26. For example, to use the SAT with a threshold value of $10 \mathrm{in}$. that begins accumulating from October 1 of each year, replace 0,0 on line 25 with 10,1 and replace 0 on line 26 with 10.0 . See table 2 for additional information on specifying the AWI and the SAT. 


\section{Timing Corrections}

Lines 32-34 provide options for the user if the data is analyzed in a different time zone or information is missing from the dataset. Line 32, the time zone offset, is the number of hours of difference between the time zone of the precipitation gages (weather stations) and the computer analyzing the data or other reference time zone, such as Coordinated Universal Time (UTC). In this example, the time zone offset value is 0 (zero) $\mathrm{h}$ because we are analyzing old data that were recorded with reference to local time. Also, since the year is provided in the input data, line 33 (year) is set to 0 (zero). Finally, line 34, the midnight flag values, is 2 , which will trigger the default condition that midnight is 0:00; a value of 1 corresponds to midnight $=24: 00$. The midnight flag is provided to accommodate these two different midnight conventions in use by various data collection systems.

\section{Formatting and Output File Information}

Line 35 is where users can enter their chosen output format for a file of current (or latest) conditions relative to the thresholds. If gnp 1 is chosen, the output file ThCurr.txt (table 3) will be provided, so current conditions relative to the RA and ID thresholds for all stations can be plotted on scatterplots in real-time mode. This is the default mode if no others are selected. If dgrs is entered, ThCTpairs.txt will be among the provided output files, and the current conditions for the RA threshold only can be plotted using any of the readily available interactive graphing packages and spreadsheet programs. Finally, the option gnp2 will provide a series of output files named, ThStaSS.txt, one per station, where SS is the two-digit station number. The content of these files is similar to content of the file ThCurr.txt, but having a separate file per station makes it easier to generate plots of the type shown in figure 6 that combine the time series data for a station with its current conditions. See the section of the user manual titled "Output File Formats" and table 3 for additional details.

Line 36 prompts the user about the statistics option provided by THRESH. If . TRUE . is entered here, the user will be provided with five ThTimeExXXX.txt files that give times of exceedance for various precipitation thresholds and threshold combinations as identified by the three numeric characters in the file name represented by $X X X$ (table 3 ). In addition, a file ThTimeMax.txt containing maximum daily values relative to thresholds at each station will be generated. The statistics option allows the user to study threshold exceedance over a long period of time (years), so landslide occurrence can be compared to threshold exceedance to determine the validity of threshold models and parameters for a particular study area.

When using the statistical mode, it is necessary to remove certain output files from previous runs of the program THRESH; first of these is the file Thlast.txt. Otherwise, the program THRESH will operate only on any new data it detects and will not generate a complete set of outputs regarding threshold exceedance. Next is the series of files, ThArchiveSS.txt, where SS is the two-digit station number. If these files are not removed, new output will be appended onto the old, which causes files to grow rapidly with the added inconvenience of either having duplicate output (if all inputs and parameters have stayed the same) or needing to separate output from successive runs of the program THRESH with different parameters in order to interpret the results.

Line 37 of thresh_in.txt can be used to activate forecast mode. As the data files provided in the example are from the past, this value is set to . FALSE. Additional information about running in forecast mode is explained in the section on operating modes and in a later example (appendix 2).

\section{Input Data Information and Output File Path}

The final section of the initialization file contains the name and location of the input data files and the desired location of the output files. Line 38, labeled Name of Output_Folder, is the path to the folder where the user wishes to place all output files. We commonly use a folder called data (or output), which is located in the working directory where the file thresh_in.txt is located (LandslideThresholds/data/test/data/ in this example). Line 39 is a heading for the list of input files on succeeding lines. It should not be changed or deleted, and no other parameters should be entered on that line. The final lines (this example has four) contain the station number, station name, and file path name for each input file, respectively. The initialization file has the correct inputs for this example on lines 40-43. It is good practice to place the input files in the same directory as the initialization file (indicated by the "./" preceding the file names), as in this example. However, the files may be placed in any other convenient location by specifying either a full or relative path name.

After you finish examining or editing the file thresh in.txt in the folder LandslideThresholds/data/test/, close the file and save any changes that you want to keep.

\section{Using THRESH to Analyze Precipitation Thresholds}

Please see the subsection on "Installation and Dependencies" in the "Introduction" of this report for more information before attempting to run programs or scripts described in the following section.

After the preparation of the initialization file is complete, THRESH must be run from the command line using the Microsoft ${ }^{\circledR}$ Windows ${ }^{\circledR}$ command prompt (or shell on any Linux or Unix system). After these data files are processed by THRESH and the threshold calculations are completed, the Python script test.py will draw several graphs (using the software library matplotlib) for visual analysis. For examples of these plots, see figures 5-8. To run this script correctly, type three commands, listed below: 
1. Include Anaconda in the search path (the list of folders or directories where the shell or command prompt looks for commands) so the shell can find the correct Python interpreter (note that the syntax of the export command may differ depending on your computer's operating system);

2. Change the working directory to the location of the input files by using the change directory command $(c d)$ followed by the path name of the folder containing your initialization file (data/test $/$ ); and

3. Invoke Python to run the script, test.py, which is in the directory LandslideThresholds/src/pyth_scripts/.

If you copied the LandslideThresholds folder to the Documents folder in your home directory, the commands will resemble the following with some variation, depending on the operating system and details of your local installation:

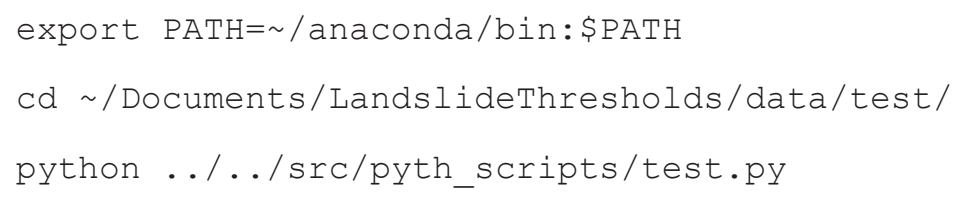

More specific examples are available in the shell scripts and Windows batch files accompanying this distribution. The same commands listed above are included in the batch file test.bat and the shell script test.sh. After typing the third command and pressing enter, the program should run to completion, and the terminal will display thresh completed normally. If the terminal displays a message stating that the program could not open the initialization file, please ensure that the file thresh_in.txt is located in the test folder. After the program has completed, the output files will be located in the data folder in test (LandslideThresholds/data/ test/data/). For further information on the output files and their contents, refer to table 3. The program will produce ThAlert.htm, ThArchiveSS.txt, ThCurrTable.htm, Thlast.txt, ThTSplot.txt, ThUpdate.txt, and ThreshLog.txt regardless of options chosen by the user in the initialization file.

In addition, the script test.py will generate a number of plots similar to those in figures 5-8 in portable network graphics (.png) format. These plots are designed to show conditions for the time period near the end of the latest input data. The file awi.png contains a time-series plot of the AWI at four weather stations for the last 15 days of available input data. In our example, the data end at midnight on December 31, 2011, and the plot shows results for December 17-31, 2011. The files boeing.png, paine.png, seatac.png, and tacoma.png contain plots of the latest conditions (colored symbol) and 15-day history of recent and antecedent precipitation at each of the four stations. The file cmtrsea.png contains a plot of the latest conditions relative to the RA precipitation threshold at all four stations. Similarly, the file idtrsea.png contains a plot of the latest conditions relative to the ID threshold. The file id_index.png contains a time-series plot of the ID index for the last 15 days. The current conditions plots are useful in continuous mode for observing how precipitation is affecting landslide susceptibility. The time-series plots give the ability to see how conditions have changed over recent days or weeks to gain added insights about current conditions.

\section{Starting a New Problem}

Now that this example is complete, you should be able to run the program THRESH with your own data. However, if you choose to use more stations (or different stations) than the ones provided in this example, the Python scripts used to plot the data will require editing of input parameters, path names, and station names in order to generate the desired graphs. The current scripts are written specifically for the four provided stations. When you receive precipitation data from your stations, be sure to convert your input data files to the same format as the sample data files provided for the example. See the section "Rainfall Input Data-File Format" in this user manual for more information on this topic.

After the preparation of the data is complete, make a copy of the initialization files, thresh_in.txt and nwsfmt_in.txt, before making any changes. It may be beneficial to give each initialization file a unique name so it can be used again for further research with that data. If none of the files in the working directory has the exact name thresh_in.txt, the program 
THRESH will prompt the user for the name of the initialization file. In addition, be sure to change any file path names and all other input parameters relevant to the project. Finally, THRESH checks for new data and will not update the output files unless it detects new data (relative to the date stored in Thlast.txt), as noted previously. Also, if there are output files from a previous run located in the data folder, please be sure to delete or move these files to a separate directory before running THRESH again. Deleting the file Thlast.txt without deleting the series of files named ThArchiveSS.txt (SS denotes the two-digit station numbers) will result in a duplicate (or new, if some of the input parameters have changed) copy of calculations being appended onto the archive files. To avoid this, always delete or move the file Thlast.txt and all files in the series, ThArchiveSS.txt before recomputing conditions relative to thresholds, for example after editing the file thresh_in.txt.

\section{Using the Programs THRESH and NWSFMT Without the Aid of Python Scripts}

Please see the subsection on "Installation and Dependencies" in the "Introduction" of this user manual for more information before attempting to run programs or scripts described in the following section.

For this example, we will continue working in the directory LandslideThresholds/data/ test/. The initialization file for NWSFMT (nwsfmt_in.txt), contains a subset of the entries in thresh_in.txt and should contain the same kind of information as entered for corresponding parameters in thresh_in.txt (tables 1 and 4). However, a subtle distinction in file names is important to note: NWSFMT appends $\_t$ to the names of its input files when naming output files. Thus, as noted previously, the input file KBFI.txt listed in nwsfmt_in.txt produces an output file KBFI_t.txt that is listed as an input file in thresh_in.txt. The only input that the file nwsfmt_in.txt has that is not also found in the file thresh_in.txt is the Append data? option. This is set to . TRUE., so data is continuously added on to the previous points. Both files, nwsfmt in.txt and thresh_in.txt, are (and typically should be) in the same folder, LandslideThresholds/data/test/. This folder also contains the auxiliary files needed by THRESH and NWSFMT: Colors.txt, interpolatingPoints.txt (if using a pointwise defined threshold), date.txt, and the files of raw data specified in the file nwsfmt_in.txt.

After the preparation of the initialization file is complete, run the programs NWSFMT and then THRESH using the command line as in the previous example.

1. Change the present working directory to the folder containing your initialization files using the change directory $(c d)$ command (not needed if you are still in the folder LandslideThresholds/dataltest/).

2. Type the file path to the NWSFMT executable file, and press return. The terminal should display messages indicating when the program starts and finishes.

3. After the text Program nwsfmt ended normally appears and the terminal returns the command prompt, type the path to the THRESH executable file in the terminal and press return.

Using absolute or relative paths to the executable is acceptable for either Windows or Linux/Unix operating systems. The important point is that the shell needs to know where to find the executable file. In this example, we have used relative paths indicating that the executable files are in a directory called bin that is two levels above the directory dataltest/. The three commands should look similar to the text below:

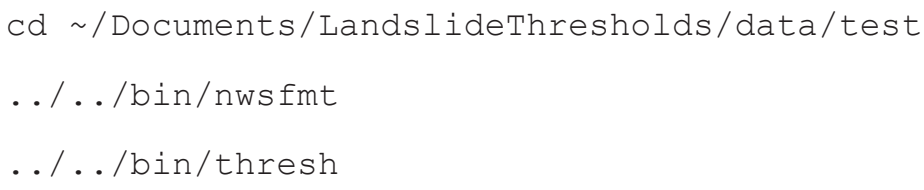

After pressing enter, the program, THRESH, should run to completion, and the last line of output in the terminal will read, thresh completed normally. As before, if the terminal displays a message indicating that the program could not open the initialization file, 
ensure that the file thresh in.txt is located in the folder LandslideThresholds/data/test/. After the program has completed, the output files will be located in the folder LandslideThresholds/ dataltest/data/. For further information on the output files and their contents, refer to table 3.

\section{Starting a New Problem}

Now that this example is complete, you should be able to run NWSFMT and THRESH with your own data. When you receive precipitation data from your stations, be sure to put the files into the same format as the sample data files provided for the example. See the section "Rainfall Input Data-File Format" in this user manual for more information on this topic.

After the preparation of the data is complete, make a copy of the initialization file (thresh_in.txt) before making any changes. Be sure to change any file path names and all other input parameters relevant to the project. Two practices might be helpful for keeping input and output organized: (1) give each initialization file a unique name so it can be reused for further research with the corresponding data and (2) copy the log file to the corresponding output folder. Finally, before running THRESH again with the same input data and new parameters, be sure to delete or move output files from the previous run or direct the output to a new folder. 


\section{Appendix 2. Example of Using Rainfall Forecasts with Thresholds}

This appendix gives an example from Seattle, Washington, of using rainfall forecasts with rainfall measurements to project conditions 24 hours (h) into the future. Please see the subsection on "Installation and Dependencies" in the "Introduction" of this report for more information before attempting to run programs or scripts described in the following section. In addition, for this section, the user must install the Python module xml todict. Please refer to the file LandslideThresholds/src/pyth_scripts/ReadMe.md for installation instructions.

This example demonstrates how to use THRESH with rainfall forecast data to forecast threshold possible exceedance. First, we'll obtain recent observations from the National Weather Service (NWS) website using the script NWS.py. This Python script will automatically run THRESH after obtaining precipitation data from the NWS website and changing it into a format that can be analyzed by THRESH (the data files provided in the test folder will not be used).

1. Before we start, open the folder named Forecast (LandslideThresholds/data/Forecast), and find the initialization file (thresh_in.txt).

2. Open and examine the file to ensure that the Forecast? option is set to . TRUE. and the Statistics? option is set to . FALSE. In addition, all input files listed at the end of the file thresh_in.txt should consist of station names followed by ft.txt, as opposed to the _t.txt found in the previous example.

3. After ensuring that the number of stations is set to 4 (four), the readings per hour is set to 1 (one) and the precipitation unit is in inches (in), the threshold tracking and forecasting scripts may be run from the terminal or command prompt using the commands below:

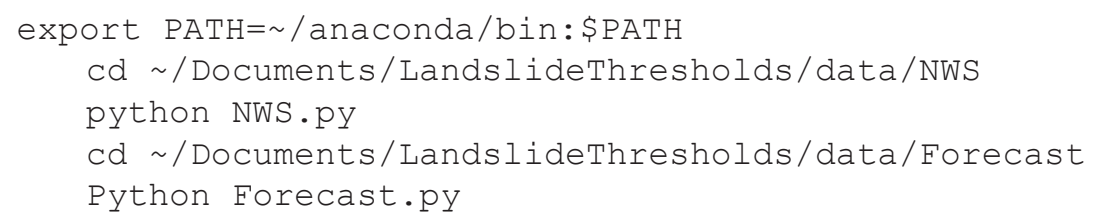

The commands listed above are a subset of those contained in the shell script rain.sh (or batch file, rain.bat). The Python script Forecast.py extracts tabular (extensible markup language $[\mathrm{XML}]$ style) weather forecast pages from https://www.weather.gov and parses them to obtain data on probability of precipitation and quantitative precipitation forecasts. The script will first provide a graph of the probability of precipitation over time for each station (labeled pop.png). Next, the forecast values will be concatenated to the current precipitation conditions from the NWS and processed in THRESH. The final outputs include a graph (forecast.png) that plots the current and forecasted recent and antecedent precipitation values for each station. If these values exceed the threshold line in the plot, then there is an increased likelihood of landslides in that particular area. Note that obtaining meaningful results depends on obtaining a long-enough record of precipitation (18 days in this example) to compute the recent and antecedent precipitation totals. In addition, the script Forecast.py will create several time-series plots in which the background will become yellow along the right edge of each plot where the input data changes from observed conditions to a forecast. These include precipitation plots for each station (named boeing_f.png, paine_f.png, seatac_f.png, and tacoma_f.png), a file named id_index_f.png containing the intensity-duration (ID) threshold index at each station, and a file named awi_f.png shows the antecedent water index (AWI) of each station. If the data exceeds the AWI threshold of 0.02 , the chance of landslides increases in this area.

The scripts NWS.py and Forecast.py may be used as templates for other areas; however, as noted previously, they will require considerable editing to customize them. Modifying the scripts to handle precipitation measurements and forecasts in different formats than those used in this example will require particular attention. 


\section{Appendix 3. Hydrological Monitoring Sites}

Please see the subsection on "Installation and Dependencies" in the "Introduction" of this user manual for more information before attempting to run programs or scripts described in the following section.

This example demonstrates using the program THRESH and accompanying plotting routines with hydrological monitoring data. The distribution package of THRESH includes sample data in the Remote Automated Landslide Hydrology Stations (RALHS) folder (LandslideThresholds/data/RALHS/) for two basic weather stations that measure precipitation and temperature only and two hillside stations with an array of hydrologic instruments including rain gages, soil water content sensors, tensiometers, and piezometers (Mirus and others, 2016; Smith and others, 2017a, 2017b). The shell script named data.sh (or batch file data.bat for Microsoft ${ }^{\circledR}$ Windows $^{\circledR}$ ) coordinates all of the necessary functions to copy, filter, process, and plot these data once they have been collected from the remote stations. Describing and explaining the data collection process is beyond the scope of this report because the process requires additional vendor-specific datalogger support software. After your data collection is up and running, the shell script can be scheduled using cron (on Unix or Linux), or the batch file can be scheduled either in your datalogger support software or as a Windows scheduled task. The shell script or batch file might require editing to make paths agree with specifics of your installation. Windows users should refer to additional setup instructions in the THRESH software repository (https://doi.org/10.5066/F7Q23XR0 or at https://github.com/usgs/landslides-thresholds).

In addition to the sample data, the folder data/RALHS/ contains copies of the files thresh_in.txt, Colors.txt, and interpolatingPoints.txt configured for the four monitoring stations. The sample data have been filtered to the point of being ready to process and plot because, as noted previously, we are not able to demonstrate the data collection process here. To perform the processing and plotting steps, enter the following commands into your command line or terminal (paths on the first two lines below and syntax of the export command may be different on your system):

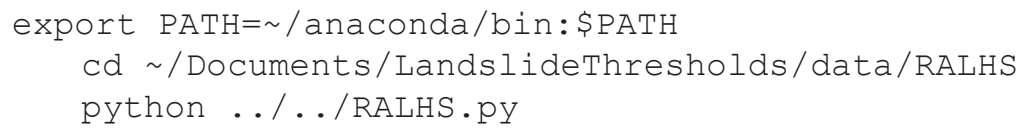

This file will provide the same kinds of plots as the script NWS.py. For more information on these plots, please refer to figures 5-8 in the main text. Other Python scripts listed in table 8 are templates for generating time-series plots of other kinds of landslide monitoring data similar to figure 8 . 
Publishing support provided by the Science Publishing Network, Denver Publishing Service Center

For more information concerning the research in this report, contact the

Center Director, USGS Geologic Hazards Science Center

Box 25046, Mail Stop 966

Denver, CO 80225

(303) 273-8579

Or visit Geologic Hazards Science Center website at https://geohazards.cr.usgs.gov/ 


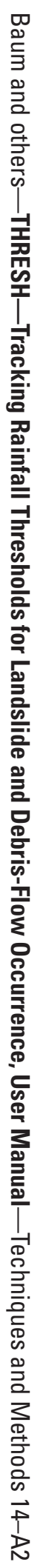

